This is a peer-reviewed, accepted author manuscript of the following article: Ragni, L., Micozzi, F., Tubaldi, E., \& Dall'Asta, A. (2020). Behaviour of structures isolated by HDNR bearings at design and service conditions. Journal of Earthquake Engineering. https://doi.org/10.1080/13632469.2020.1776792

\title{
BEHAVIOUR OF STRUCTURES ISOLATED BY HDNR BEARINGS AT DESIGN AND SERVICE CONDITIONS
}

\section{Laura Ragni ${ }^{1}$, Fabio Micozzi ${ }^{2}$, Enrico Tubaldi ${ }^{3}$, Andrea Dall'Asta ${ }^{2}$}

${ }^{1}$ Department of Construction, Civil Engineering and Architecture, Università Politecnica delle Marche, Ancona, Italy

${ }^{2}$ School of Architecture and Design, University of Camerino, Ascoli Piceno, Italy

${ }^{3}$ Department of Civil and Environmental Engineering, University of Strathclyde, Glasgow, UK

High Damping Natural Rubber (HDNR) bearings are widely employed for seismic isolation. These bearings are characterized by a remarkable nonlinear behaviour and often by a degrading cyclic response, induced by the addition of filler to enhance its dissipation capacity. This latter phenomenon, denoted as stress-softening or Mullins effect, can significantly influence the nonlinear dynamic response of isolated structures leading to a variability of the seismic response of isolated buildings. Moreover, the behaviour of HDNR bearings may produce an amplification of response, due to higher modes contribution, which can affect the performance of non-structural components and equipment. Models providing an accurate description of the nonlinear behaviour of HDNR bearings with significant stress-softening have been proposed only recently. Thus, the studies in the literature are generally based on simplified models. In this paper, an advanced HDNR model, accounting for variation of stiffness and damping with the strain amplitude and deformation history, is used to analyse the seismic performance of isolated structures at different intensity levels. First, a parametric analysis is carried out on a two-degree of freedom system to study different configurations of practical interest. Subsequently, a multi-degree of freedom system representing a realistic building is analysed to evaluate the response at different floors andthe contribution of higher modes of vibration. The influence of practical aspects, such as the superstructure damping and the friction of the sliders, is also investigated.

\section{KEYWORDS}

Seismic isolated structures, High damping rubber bearings, Mullins effect, Stress-softening, Equivalent linear models

\section{INTRODUCTION}

High Damping Natural Rubber (HDNR) bearings are widely recognized as a technology able to protect buildings from the damaging effects of earthquakes. The number of isolated buildings is increasing in many seismically active countries and the most common bearings used are Lead Rubber (LR) bearings, Concave Curved Surface (CCS) bearings, and Low Damping or High Damping Natural Rubber (LDNR or HDNR) bearings [1]-[2]. These isolation devices, employed alone or in combination with dampers, have been proven to be very effective in protecting the building structure under severe seismic inputs. However, one aspect that deserves further investigation is the influence of the variability of the bearings behaviour on the response of the isolation system and the superstructure, which significantly influence the seismic risk evaluation, as recently observed for isolated structures [3]-[4] as well as structures with other dissipative systems [5]-[6]. In LR bearings, this variability is e.g. due to the temperature increment leading to a decrement of the yield stress of the lead, whereas in CCS bearings the friction coefficient may vary due to the temperature, the velocity or the axial load acting on the bearings [1],[7]-[9]. In the 
HDNR bearings, which are examined in this paper, the variability of the response is caused by fillers such as carbon black added to rubber compounds to increase their energy dissipation capacity. The addition of fillers often induces a degradation of the cyclic response of the bearings, due to an internal damage process occurring in the rubber. This effect, known as stress-softening, scragging or Mullins effect [10]-[11], characterizes the virgin rubber or a rubber that has recovered the original properties after a sufficient time of rest [11]-[12]. In many countries this phenomenon is addressed by design codes [13]-[14]; for example the European code of anti-seismic devices [13] imposes a limitation in order to ensure the stability of the shear properties under repeated cycles. Some recent works [15]-[17] showed that scragging may significantly affect the bearing response also in the case of fiber-reinforced elastomeric isolators. Some advanced models of HDNR bearings [18]-[19] are currently available in the Opensees platform [20]. However, the first one [18] does not account for any scragging, even though the same authors of this model developed an analytical formulation in a previous study [21] to account for the load history dependence. The second model [19] accounts for the stress-softening (decomposed into "Mullins effect" and "scragging"), though by introducing some approximations. Recently, an accurate nonlinear and history dependent constitutive law has been developed by the authors [12], [22] for describing the HDNR material behaviour. In particular, the model refers to a compound with significant stresssoftening but complying with the European code on anti-seismic devices [13]. This model has been calibrated against the results of experimental tests carried out on several virgin rubber pieces and uses multiple damage parameters to simulate the stress-softening including its direction dependence. Some demonstrative applications on an isolated single degree of freedom (S-DOF) system subjected to seismic inputs of different characteristics have also been carried out. In this paper, the model is used to study the history dependent response of more realistic isolated systems, modeled as 2-DOF and M-DOF systems.On this regard, it should be noted that under service and design conditions the shear load-deflection behaviour of a laminated HDNR bearing with sufficiently high shape factors [25][26] is the same as that of a block, constrained to be in simple shear, of the same total thickness, cross-sectional area and material properties as the rubber in the bearing. This allow the use of the material model to simulate the response of the HDNR bearings, as done in this paper. In fact, under these conditions the effects of axial load and bending moment on the shear-load behaviour of such a single rubber layer in the bearing are negligible and the extra compliance resulting from $\mathrm{P}-\Delta$ effects theory are small.

Another important topic, not fully investigated to date, is the effectiveness of the isolation system to protect equipment and other sensitive non-structural components in case of moderate (frequent) events, especially for strategic buildings, such as hospital or industrial facilities. On this regard, the use of LR and CCS devices for isolating these buildings may be problematic due to the variation of stiffness and damping they exhibit at different displacement amplitudes [7]. In fact, these devices provide optimal values of stiffness and damping only at the design displacements, while they provide very large values for small displacements, causing a significant increment of floor accelerations [23]. In addition, their strongly nonlinear behaviour may lead to an amplification of the higher modes response, especially in flexible superstructures, which can further reduce the performance of non-structural component and equipment of the building [23]. Differently for both LDNR and HDNR bearings, the stiffness increases at very large and very small strains, but the damping usually decreases [7] [23]. However, HDNR bearings also show a strongly nonlinear behaviour, which can yield to an amplified response in flexible superstructures. The performance of non-structural components and equipment of systems isolated with HDNR bearings at intensity levels typical of the serviceability limit state has been investigated in the past but only by using simplified bearing models, such as linear viscoelastic models [7],[23] or elastoplastic models [24]. In this paper, the advanced model developed by some of the authors [12],[22] 
and accounting for all the nonlinear effects as well as the stress-softening of the bearings is also used to investigate the performance non-structural components (including equipment) of structures isolated with HDNR bearings at service and design condition.

In particular, in the first part of the paper a parametric analysis is performed on simple two-degree of freedom (2-DOF) systems by considering different configurations of practical interest (from rigid to flexible superstructures). Then, in the second part of the paper, a multi-degree of freedom (M-DOF) system representing a realistic flexible building (6 storeys r.c. building) with a hybrid isolation system (HDNR bearings and low friction flat sliders) is analysed. All the investigated systems are designed by following the European and national design codes [13], [27], [28], i.e. by considering seismic actions at the Ultimate Limit State (ULS) for the superstructures and up to the Collapse Limit State (CLS) for the bearings, and HDNR properties at the third cycle of harmonic at the design shear strain amplitude. Nonlinear dynamic analyses are then carried out under a set of real ground motion records scaled to different intensity levels, with return periods ranging from the Operational Limit State (OLS) to the Collapse limit state (CLS). The shear deformation of the isolation system is monitored as well as the superstructure absolute floor accelerations and interstorey drifts in order to assess the performance of structural and nonstructural components [29]. All results are given in terms of average values and dispersion. Moreover, mean response floor spectra of the superstructure are evaluated to investigate the performance of flexible contents inside the building [30]. In order to quantify the effects of the nonlinear behaviour of HDNR bearings, in the parametric analysis involving the 2-DOF systems, all results are compared with those obtained by using a reference linear viscoelastic model equivalent to the HDNR model at the design conditions. Finally, results of the analysis carried out on the M-DOF system are compared to the ones obtained with the equivalent 2-DOF system to highlight the influence of higher order modes of vibration. Other aspects characterizing a real application, such as the influence of the superstructure damping and the sliders friction, are also investigated.

\section{PARAMETRIC STUDY}

In this section, a parametric analysis is carried out by considering 2-DOF systems representing isolated structures with different properties. The 2-DOF systems are described first, then the design of the isolation system and the superstructure is illustrated, followed by the description of the seismic input used for the analyses. Finally, the results of the parametric study are reported, shedding light on the influence of the HDNR nonlinear behaviour on the main response parameters of the system as well as on floor response spectra (FRS), related to the performance of accelerationsensitive components.

\section{2-DOF system models considered in the parametric analysis}

Figure 1 shows the two-mass structural model considered in this study. Using the same notation of [2], $m$ and $m_{b}$ represent the mass of superstructure and of the base floor above the isolation system, respectively and $\mathrm{M}=m+m_{b}$ is the total mass. The absolute displacements of the two masses are denoted by $u_{b}$ and $u_{s}$, whereas relative displacements are defined as $v_{b}=u_{b}-u_{g}$ and $v_{s}=u_{s}-u_{b}$, where $u_{g}$ is the ground displacement. The superstructure is described by a linear elastic model, with stiffness $k_{s}$ and damping $c_{s}$, whereas the force-displacement behaviour of the isolator $F_{b}-v_{b}$ is derived from a recent constitutive model expressing the relation between the shear stress $\tau_{b}$ and shear strain $\gamma_{b}$ for a HDNR compound commonly used for seismic isolation bearings [12], [22]. The bearing displacement $v_{b}=\gamma_{b} \cdot h_{i s}$ is given by the product between the rubber shear strain $\gamma_{b}$ and the total rubber thickness $h_{i s}$, whereas the total horizontal force $F_{b}=\tau_{b} \cdot A_{i s}$ of the isolation system is given by the product between the shear stress $\tau_{b}$ and the total rubber area $A_{i s \text {. As already }}$ 
discussed in the Introduction, this approach of deriving the bearing horizontal response from the shear constitutive law of the rubber layers, is correct for HDNR bearings with adequate shape factors [25][26] and far from collapse conditions, where axial loads and bending moments become important, also due to P-Delta effects. In particular, the adopted compound exhibits a significant dissipation capacity, associated to a significant stress-softening. Nevertheless, the compound behaviour complies with the prescription of the European code on anti-seismic devices [13] about the stability of the shear properties under repeated cycling, requiring a ratio between the minimum and the maximum shear modulus measured between the first and the tenth cycle of imposed harmonic strains not less than 0.6. The HDNR compound is also characterized by the typical stiffer behaviour at low shear strain amplitudes (less than 100\%) and the hardening behaviour at large shear strain amplitudes (above 200\%).
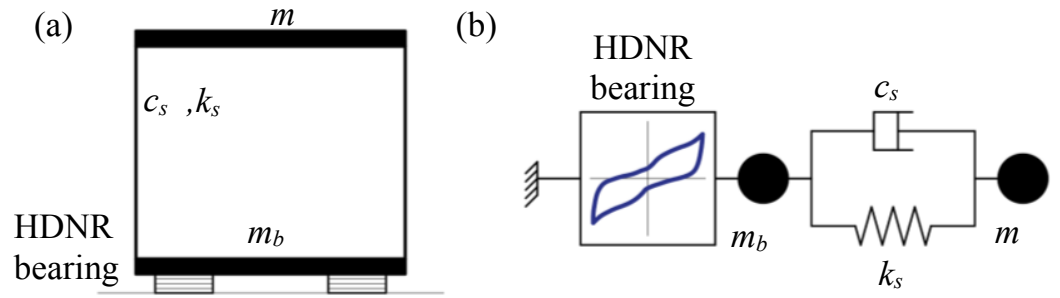

Figure 1 - (a) Isolation system and (b) 2-DOF model.

Figure 2 illustrates the numerical hysteresis loops of virgin HDNR samples subjected each one to a maximum shear deformation ranging from $25 \%$ to $250 \%$. For low shear strain amplitudes (Figure 2a), the secant stiffness to maximum deformation decreases for increasing strain amplitudes and the stress-softening is limited. Differently, at large strain amplitudes, a hardening behaviour is observed and the stress-softening is more significant (Figure 2b). Cycles are carried out with a period equal to the isolation one. Nevertheless, this rubber compound shows a negligible dependence on the shear strain rate [12]. Figure 3 shows the equivalent linear proprieties of the HDNR compound for different strain amplitudes and loading cycles. In particular, Figure $3 a$ reports values of the secant shear modulus $\left(G_{i s}\right)$, whereas Figure $3 \mathrm{~b}$ reports the values of the equivalent damping ratio $\left(\xi_{i s}\right)$, defined according to [13],[31] by the following expressions:

$$
\begin{aligned}
G_{i s} & =\frac{\tau_{b, \max }-\tau_{b, \min }}{\gamma_{b, \max }-\gamma_{b, \mathrm{mn}}} \\
\xi_{i s} & =\frac{2 W_{D}}{\pi G_{i s}\left(\gamma_{b, \max }-\gamma_{b, \min }\right)^{2}}
\end{aligned}
$$

where $W_{D}$ is the energy dissipated in each cycle. The equilibrium equations governing the response of the 2-DOF systems under the generic ground motion "

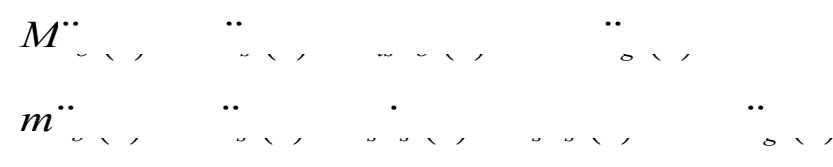

This can be rewritten as:

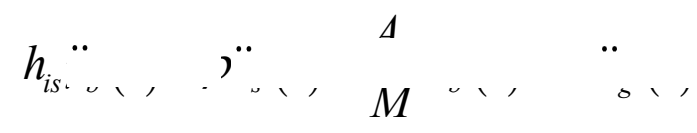


$h_{i s .}{ }^{*}, \quad \cdots, \quad \ldots, \ldots, \ldots, \quad \ldots$,

where $\omega_{s}=2 \pi / T_{s}$ and $\xi_{s}=c_{s} / 2 m \omega_{s}$ are the circular frequency and damping ratio of the fixed-base superstructure, and

$\rho=\frac{m}{M}=\frac{m}{m_{b}+m}$

denotes the ratio between the top mass and the total mass (called $\gamma$ in [2]). For the purpose of this parametric study, the geometric properties of the isolated system have been assigned to obtain a target isolation period equal to $T_{i s, d}=2.5 \mathrm{~s}$. In order to cover configurations of practical interest, the superstructure stiffness is calibrated to obtain values of the vibration period of the fixed-base superstructure $\left(T_{s}=2 \pi / \omega_{s}\right)$ ranging from $0.25 \mathrm{~s}$ and $1 \mathrm{~s}$. More in detail, the superstructure stiffness per unit total mass can be calculated as follows:

$\frac{k_{S}}{M}=\omega_{S}^{2} \rho$

The superstructure damping is given by the following expression:

$c_{s}=\frac{2 \xi_{s}}{\omega_{s}} k_{s}$

Following the recommendations of [32], a damping proportional to the superstructure stiffness is employed. For all the cases considered the damping coefficient is set equal to $\xi_{s}=2 \%$ [33]. Table 1 summarizes the superstructure properties for the three considered cases and for a unit total mass.
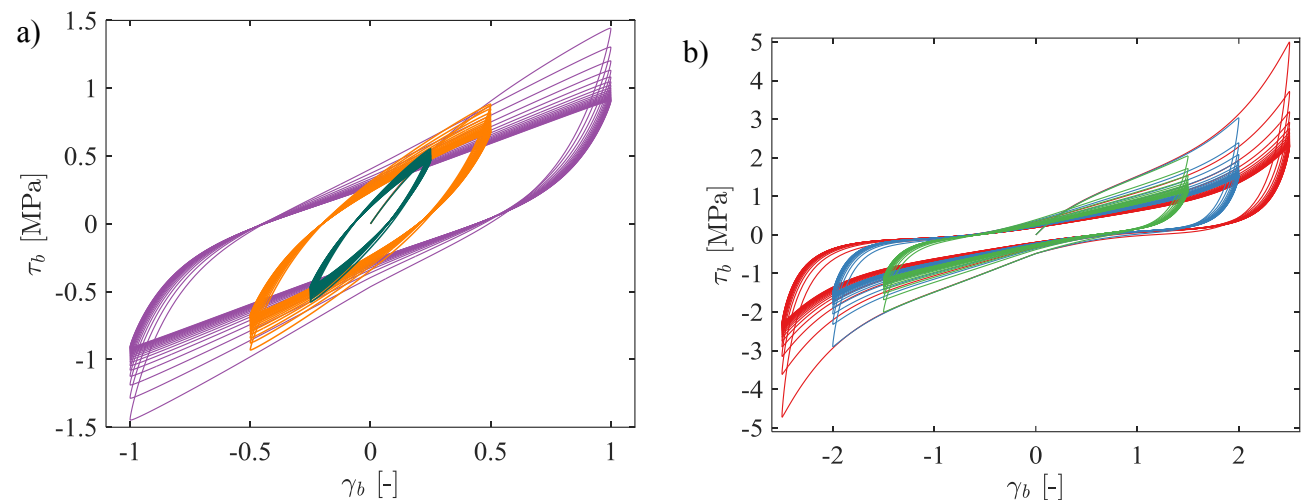

Figure 2 - Hysteresis loops of virgin HDNR at different strain amplitudes: (a) 25\%, 50\% and $100 \%$ and (b) $150 \%, 200 \%$ and $250 \%$.

a)

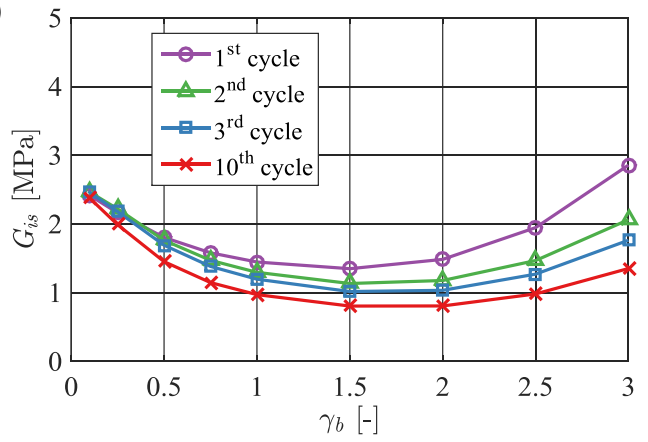

a)

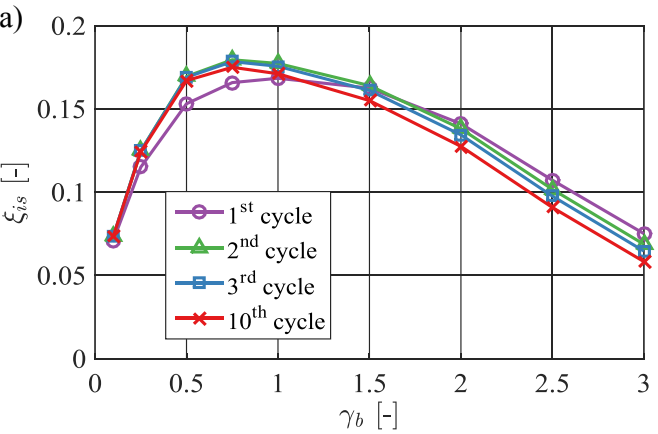


Figure 3 - Equivalent linear parameters at different strain amplitudes and cycles: (a) equivalent shear modulus and (b) equivalent damping ratio

Table 1 - Superstructure properties per unit mass.

\begin{tabular}{cccccc}
\hline & $T_{s}$ & $\omega_{s}$ & $\rho$ & $k_{s}$ & $c_{s}$ \\
& {$[\mathrm{~s}]$} & {$\left[\mathrm{s}^{-1}\right]$} & {$[-]$} & {$[\mathrm{kN} / \mathrm{m}]$} & {$[\mathrm{kNs} / \mathrm{m}]$} \\
\hline case $a$ & 0.25 & 25.12 & 0.5 & 315.83 & 0.5027 \\
case $b$ & 0.50 & 12.56 & 0.6 & 94.75 & 0.3016 \\
case $c$ & 1.00 & 6.28 & 0.7 & 27.64 & 0.1759 \\
\hline
\end{tabular}

\section{Design of the isolation system and equivalent linear model}

The isolation system is dimensioned to attain under the ULS a value of the shear deformation equal to $\gamma_{b, d}=1.5$ for all the considered cases. This corresponds to a value of the equivalent shear modulus close to the minimum (Figure $3 \mathrm{a}$ ), and to a value of the equivalent damping ratio close to the maximum (Figure 3b). Thus, the value of $\gamma_{b, d}$ is close to optimal one in order to protect the superstructure, whose structural safety must be guaranteed up to the ULS limit state, according to European and nation design codes [27],[28]. Moreover this design values it is lower than the limit of $2.5 / \gamma_{x}$ imposed by the European code on anti-seismic devices [13], where $\gamma_{x}$ is equal to 1.2 and is the reliability factor prescribed by the same code. It is noted that this last requirement is analogous to the prescription of the national design code, which imposes to verify that the maximum shear strain is lower than 2.5 at the CLS, as show in the next section. It is noted that in real isolated buildings possible torsional effects due to accidental eccentricities must be also considered, then $\gamma_{b, d}$ becomes the average shear strain of bearings and it must be sufficiently lower than the limit value imposed by the code, such that the maximum shear strain also complies with the prescription.

According to European codes [13],[27], the design action corresponding to the ULS of the Eurocode 8 [27] is characterized by an exceedance probability of $10 \%$ in 50 years or a return period $T_{R}=475$ year. In particular, a Type 1 spectrum [27] with a peak ground acceleration on stiff soil of $0.35 \mathrm{~g}$ and soil $\mathrm{C}$ conditions are considered. The corresponding peak ground acceleration at the building site is equal to $a_{g}=0.35 \mathrm{~g} \cdot 1.15=0.403 \mathrm{~g}$. Moreover, following the indications given by the EN15129 [13], the design of the isolation system has been carried out by considering nominal values of the equivalent linear properties calculated at the third cycle of imposed cyclic deformations carried out at the selected design shear strain and design period. For the considered rubber compound, the design equivalent shear modulus and the design equivalent damping ratio are respectively $G_{i s, d}=1 \mathrm{MPa}$ and $\xi_{i s . d}=16 \%$. By considering the superstructure as infinitely rigid, and lumping the total mass $M$ over the isolation system, the structure reduces to a S-DOF system and the isolation system displacement can be estimated from the displacement spectrum corresponding to the target isolation period $\left(T_{i s, d}=2.5 \mathrm{~s}\right)$ and the damping ratio of the isolation system $\left(\xi_{i s, d}=16 \%\right)$. The obtained displacement is $u_{b, d}=0.207 \mathrm{~m}$, and the total rubber thickness is $h_{i s}=u_{b, d} / \gamma_{b, d}=0.138 \mathrm{~m}$. Consequently, the total rubber area per unit total mass can be obtained through the following expression:

$$
\frac{A_{i s}}{M}=\left(\frac{2 \pi}{T_{i s, d}}\right)^{2} \frac{h_{i s}}{G_{i s, d}}
$$

The obtained value for unit total mass is $A_{i s}=0.00086 \mathrm{~m}^{2}$. The diameter of HDNR bearings is defined based on the effective mass to be isolated according to stability criteria and limits on 
compressive stresses provided by the codes, as illustrated in [34] for the Eurocode. In addition, the number of elastomeric bearings may be lower than the number of columns of the superstructure following as a result of the use of flat sliders (hybrid isolation system) to increase the range of reachable isolation periods. This solution, as show later in the design of the case study, allows to maintain the compression stresses under values causing the buckling of the bearings.

Finally, in order to verify the outcomes of the design, an equivalent Linear Visco-Elastic (LVE) model of the isolation system at the design shear strain $\left(\gamma_{b, d}\right)$ can be defined, with stiffness $k_{i s, d}$ and damping constant $c_{i s, d}$, evaluated as follows:

$$
\begin{aligned}
& k_{i s, d}=\frac{G_{i s . d} A_{i s}}{h_{i s}} \\
& c_{i s, d}=\frac{2 \xi_{i s, d}}{\omega_{i s, d}} k_{i s, d}=\frac{\xi_{i s, d} T_{i s, d}}{\pi} k_{i s, d}
\end{aligned}
$$

The obtained values for unit total mass are $k_{i s, d}=6.32 \mathrm{kN} / \mathrm{m}$ and $c_{i s, d}=0.81 \mathrm{kNs} / \mathrm{m}$. By using these equivalent linear properties, the 2-DOF system becomes a linear system and its modal properties at the design condition can be evaluated. However, since the system is non-classically damped, complex modal analysis must be carried out to evaluate the complex frequencies and vibration modes [35]. This analysis is based on a state-space representation of the dynamical system, which also provides information on the modal damping ratios in the isolated system [32]. The results of the complex modal analysis of the 2-DOF system at design conditions are reported in Table 2 (bold values) for case $c$.

It is worth to observe that the values of the period and damping ratio relevant to the first mode are slightly different than the design ones, due to the influence of the superstructure, and that the values relevant to the second mode of vibration are very different from those corresponding to the fixed superstructure, due to the contribution of the isolation system [2]. In the same table, the modal analysis results obtained by considering an equivalent LVE model calibrated at conditions different from the design one $\left(G_{i s}\right.$ and $\xi_{i s}$ are evaluated by considering values of $\gamma_{b}$ between $50 \%$ and $300 \%$ and different cycles of deformation) are also reported. These results provide an important insight into the influence of the nonlinear HDNR behaviour on the dynamic properties of the isolated systems, and will be useful for discussing the seismic response of the systems at different seismic intensity levels reported in the next subsections.

\begin{tabular}{|c|c|c|c|c|c|c|c|c|c|c|c|c|}
\hline \multirow[b]{2}{*}{$\begin{array}{l}\gamma_{b} \\
{[-]}\end{array}$} & \multicolumn{4}{|c|}{ 1st cycle } & \multicolumn{4}{|c|}{ 3rd cycle } & \multicolumn{4}{|c|}{ 10th cycle } \\
\hline & $\begin{array}{l}T_{1} \\
{[\mathrm{~s}]}\end{array}$ & $\begin{array}{c}\xi_{1} \\
{[-]}\end{array}$ & $\begin{array}{c}T_{2} \\
{[\mathrm{~s}]}\end{array}$ & $\begin{array}{c}\xi_{2} \\
{[-]}\end{array}$ & $\begin{array}{c}T_{1} \\
{[\mathrm{~s}]}\end{array}$ & $\begin{array}{c}\xi_{1} \\
{[-]}\end{array}$ & $\begin{array}{c}T_{2} \\
{[\mathrm{~s}]}\end{array}$ & $\begin{array}{c}\xi_{2} \\
{[-]}\end{array}$ & $\begin{array}{c}T_{1} \\
{[\mathrm{~s}]}\end{array}$ & $\begin{array}{c}\xi_{1} \\
{[-]}\end{array}$ & $\begin{array}{c}T_{2} \\
{[\mathrm{~s}]}\end{array}$ & $\begin{array}{c}\xi_{2} \\
{[-]}\end{array}$ \\
\hline $300 \%$ & 1.73 & $5.0 \%$ & 0.47 & $9.7 \%$ & 2.08 & $5.0 \%$ & 0.50 & $7.8 \%$ & 2.33 & $4.8 \%$ & 0.51 & $6.9 \%$ \\
\hline $250 \%$ & 2.00 & $7.9 \%$ & 0.49 & $11.1 \%$ & 2.39 & $8.0 \%$ & 0.51 & $9.1 \%$ & 2.68 & $7.8 \%$ & 0.52 & $8.1 \%$ \\
\hline $200 \%$ & 2.23 & $11.2 \%$ & 0.51 & $12.4 \%$ & 2.61 & $11.4 \%$ & 0.52 & $10.6 \%$ & 2.93 & $11.2 \%$ & 0.53 & $9.4 \%$ \\
\hline $150 \%$ & 2.32 & $13.1 \%$ & 0.51 & $13.3 \%$ & 2.63 & $13.7 \%$ & 0.52 & $11.9 \%$ & 2.93 & $13.6 \%$ & 0.53 & $10.7 \%$ \\
\hline $100 \%$ & 2.25 & $13.4 \%$ & 0.51 & $14.0 \%$ & 2.45 & $14.5 \%$ & 0.52 & $13.5 \%$ & 2.68 & $14.7 \%$ & 0.52 & $12.3 \%$ \\
\hline $75 \%$ & 2.17 & $12.9 \%$ & 0.51 & $14.3 \%$ & 2.30 & $14.3 \%$ & 0.51 & $14.4 \%$ & 2.49 & $14.6 \%$ & 0.52 & $13.2 \%$ \\
\hline $50 \%$ & 2.06 & $11.5 \%$ & 0.50 & $14.1 \%$ & 2.11 & $12.9 \%$ & 0.50 & $14.9 \%$ & 2.25 & $13.3 \%$ & 0.51 & $13.9 \%$ \\
\hline
\end{tabular}

Table 2- Complex modal analysis results (case $c$ ) 


\section{Seismic hazard levels}

The response of the systems described in the previous section is evaluated at different hazard levels, involving design and serviceability limit states. In particular, as introduced in the previous section, the design hazard level is that of the Ultimate Limit State (ULS) of Eurocode 8 [27], also corresponding to the Life-Safety Limit State (LSLS) of the Italian seismic code [28]. This limit state is associated to a return period $\left(T_{R}\right)$ of 475 years, corresponding to a mean annual frequency of exceedance $(v)$ equal to $0.0021 \mathrm{yrs}^{-1}$. Two hazard levels lower than the design one are also considered, the first one with $T_{R}=95 \mathrm{yrs}$ or $v=0.01052 \mathrm{yrs}^{-1}$ and used to check the Damage Limit State (DLS) of the Eurocode 8 [27], the second with $T_{R}=30 \mathrm{yrs}$ or $v=0.03333 \mathrm{yrs}^{-1}$ and relevant to the Operational limit State (OLS) of the Italian seismic code [28]. In addition to these, a hazard level larger than the design one is considered, the Collapse Limit State (CLS) with $T_{R}=975$ yrs or $v=0.00102 \mathrm{yrs}^{-1}$ according to the Italian seismic code [28], which prescribes to verify the isolation devices at this limit state. The values of the peak ground acceleration $\left(a_{g}\right)$ at return periods other than the design one are obtained by considering the following hazard curve for the:

$$
v\left(a_{g}\right)=k_{0}\left(a_{g}\right)^{-k_{1}}
$$

where $k_{1}$ is set equal to $1 / 0.35=2.857$ according to [36], and $k_{0}$ is set equal to 0.013 . The selected parameters provide a peak ground acceleration $a_{g}=0.403 \mathrm{~g}$ for $v=0.0021 \mathrm{yrs}^{-1}$, coherently with the design of the isolation system carried out in the previous section. Table 3 reports the values of $a_{g}$ corresponding to the considered limit states as well as the spectral ordinates in terms of pseudoacceleration $\left(S_{a}\right)$ calculated at the design isolation period $\left(T_{i s}=2.5 \mathrm{~s}\right)$ and for a $5 \%$ damping ratio. For completeness, pseudo-acceleration and displacement spectral ordinates calculated by also considering the equivalent damping coefficient of the isolation system ( $\xi_{i s}=16 \%$ ) are provided in the same table. These are obtained by reducing the spectrum by the factor $\eta=0.7$ [27]-[28]. The same spectral shape is assumed for all the return periods, as suggested in [27]. It should be noted that the maximum strain of bearings at the CLS, equal to $265 / 0.138=1.92$, is lower than the maximum admissible value equal to 2.5. Thus isolation bearings are verified also according to the national design code [28]. To describe the record-to-record variability, a set of 20 ground motion records are employed in the parametric study. These records have been selected from the PEER strong motion database [37] based on the following criteria: they are associated to the site class C as defined in Eurocode 8 [27], have a source-to-site distance $R$ varying in the range between 20 $\mathrm{km}$ and $50 \mathrm{~km}$ (thus records do not contain any pulse) and a moment magnitude $M_{w}$ varying in the range between 6.5 and 7.5. Records are scaled in amplitude to match the ULS spectrum at the design isolation period and damping ratio. Among all the records available for the selected scenario, the 20 selected ones are characterized by scale factors close to 1 . Record details and scale factors are reported in Table 4, whereas the response spectra of the scaled records are plotted in Figure 4 together with the average and the design spectrum.

Table 3 - Hazard levels

\begin{tabular}{ccccccc}
\hline & $T_{R}$ & $\nu=1 / T_{R}$ & $a_{g}$ & $S_{a}\left(T_{i s}, 5 \%\right)$ & $S_{a}\left(T_{i s}, \xi_{i s}\right)$ & $S_{d}\left(T_{i s}, \xi_{i s}\right)$ \\
\hline & {$[\mathrm{yrs}]$} & {$\left[\mathrm{yrs}^{-1}\right]$} & {$[g]$} & {$[g]$} & {$[g]$} & {$[\mathrm{m}]$} \\
\hline OLS & 30 & 0.03333 & 0.153 & 0.073 & 0.051 & 0.079 \\
DLS & 95 & 0.01052 & 0.229 & 0.110 & 0.076 & 0.118 \\
ULS & 475 & 0.00210 & 0.403 & 0.193 & 0.133 & 0.207 \\
CLS & 975 & 0.00102 & 0.516 & 0.248 & 0.171 & 0.265 \\
\hline
\end{tabular}


In order to describe the seismic scenario at the other seismic hazard levels, the same ground motions have been further scaled by a factor given by the ratio between the spectral ordinate at the considered limit state and at the design limit state, corresponding to the design isolation period and damping. Although more advanced approaches, such as the multi-stripe analysis based on the conditional mean spectrum [3]-[4] are becoming increasingly widespread for performance-based assessment studies, in this work incremental dynamic analysis (IDA) is carried out because it permits to compare results obtained at different intensity levels, thus allowing to evaluate the deviation from a response proportional to the seismic input. Moreover, it also permits to reduce the variability of the response of the reference LVE model, thus allowing to highlight the response dispersion due to the nonlinear behaviour of HDNR bearings.

Table 4 - Records details and values of the scale factor (SF) for the design input level.

\begin{tabular}{|c|c|c|c|c|c|c|c|c|c|c|}
\hline $\begin{array}{c}\text { No. } \\
-\end{array}$ & $\begin{array}{c}\text { Year } \\
-\end{array}$ & $\begin{array}{c}\text { Earthquake Name } \\
-\end{array}$ & $\begin{array}{c}\text { Station Name } \\
- \\
\end{array}$ & $\begin{array}{c}\text { PGA } \\
{[\mathrm{g}]}\end{array}$ & $\begin{array}{c}\mathrm{V}_{\mathrm{s} 30} \\
{[\mathrm{~m} / \mathrm{sec}]}\end{array}$ & $\begin{array}{c}\text { Comp. } \\
-\end{array}$ & $\begin{array}{c}\text { M. } \\
-\end{array}$ & $\begin{array}{l}\mathrm{R}_{\mathrm{rup}} \\
{[\mathrm{km}]}\end{array}$ & $\begin{array}{c}\text { RSN } \\
-\end{array}$ & $\begin{array}{c}\text { SF } \\
-\end{array}$ \\
\hline 1 & 1995 & Kobe_Japan & Morigawachi & 0.17 & 256 & 1 & 6.9 & 24.8 & 1110 & 1.18 \\
\hline 2 & 1995 & Kobe_Japan & Sakai & 0.15 & 256 & 1 & 6.9 & 28.1 & 1115 & 1.44 \\
\hline 3 & 1995 & Kobe_Japan & Yae & 0.15 & 256 & 1 & 6.9 & 27.8 & 1121 & 1.26 \\
\hline 4 & 1979 & Imperial Valley-06 & Delta & 0.26 & 242 & 1 & 6.5 & 22.0 & 169 & 1.42 \\
\hline 5 & 1979 & Imperial Valley-06 & Delta & 0.26 & 242 & 2 & 6.5 & 22.0 & 169 & 1.12 \\
\hline 6 & 1954 & Northern Calif-03 & Ferndale City & 0.19 & 219 & & 6.5 & 27.0 & 20 & 1.23 \\
\hline 7 & 1968 & Borrego Mtn & El Centro Ar & 0.09 & 213 & 1 & 6.6 & 45.7 & 36 & 1.57 \\
\hline 8 & 1992 & Landers & Indio - Jackson Road & 0.23 & 292 & 1 & 7.3 & 48.8 & 3754 & 1.21 \\
\hline 9 & 2004 & Niigata Japan & NIG018 & 0.13 & 198 & 1 & 6.6 & 25.8 & 4208 & 0.97 \\
\hline 10 & 1989 & Loma Prieta & Agnews State Hospital & 0.16 & 240 & 2 & 6.9 & 24.6 & 737 & 0.83 \\
\hline 11 & 1989 & Loma Prieta & Hollister - South \& Pine & 0.29 & 282 & 1 & 6.9 & 27.9 & 776 & 0.82 \\
\hline 12 & 1989 & Loma Prieta & Hollister - Sou & 0.29 & 282 & 2 & 6.9 & 27.9 & 776 & 1.54 \\
\hline 13 & 1989 & Loma Prieta & Hollister Cit & 0.23 & 199 & 1 & 6.9 & 27.6 & 777 & 1.40 \\
\hline 14 & 1989 & Loma Prieta & Hollister City Hall & 0.23 & 199 & 2 & 6.9 & 27.6 & 777 & 0.96 \\
\hline 15 & 1989 & Loma Prieta & Hollister Differential Array & 0.28 & 216 & 1 & 6.9 & 24.8 & 778 & 1.12 \\
\hline 16 & 1989 & Loma Prieta & Hollister Differential Array & 0.28 & 216 & 2 & 6.9 & 24.8 & 778 & 1.59 \\
\hline 17 & 1989 & Loma Prieta & anyvale - $\mathrm{Co}$ & 0.21 & 268 & 1 & 6.9 & 24.2 & 806 & 0.82 \\
\hline 18 & 1989 & Loma Prieta & Sunnyvale - Co & 0.21 & 268 & 2 & 6.9 & 24.2 & 806 & 0.76 \\
\hline 19 & 1992 & Cape Mendocino & Eureka - Myrtle \& West & 0.17 & 337 & 2 & 7.0 & 42.0 & 826 & 1.34 \\
\hline 20 & 1992 & Landers & Palm Springs Airport & 0.09 & 312 & 2 & 7.3 & 36.2 & 884 & 1.29 \\
\hline
\end{tabular}
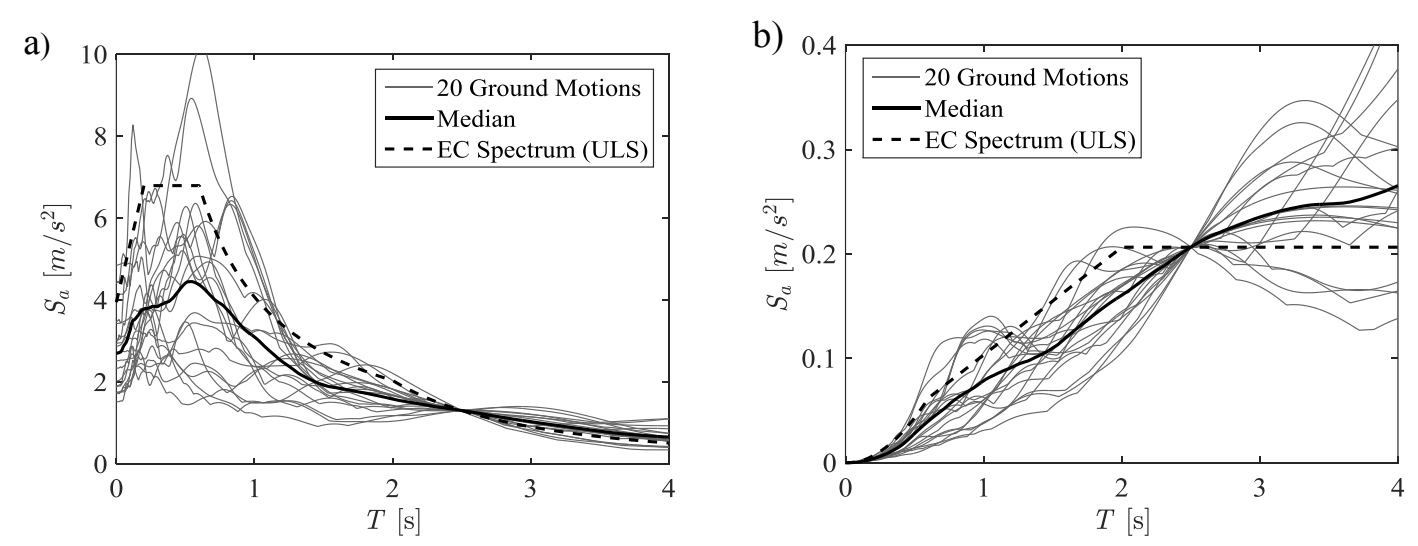

Figure 4 - (a) Pseudo-acceleration spectra and (b) displacement spectra of the scaled 20 records together with the average spectrum and EC8-type 1 design spectrum at ULS for $\xi_{i s}=16 \%$. 


\section{Parametric analysis results}

This section illustrates the results of the analyses carried out on the 2-DOF systems of Figure 1 for the different values of the superstructure period. The seismic performance of the systems is described by the bearing shear deformation $\gamma_{b}$ (reported in Table 5), the superstructure absolute acceleration $\ddot{u}_{s}$ (reported in Table 6), and the superstructure relative displacement $v_{s}$ (reported in Table 7). For each seismic intensity level considered, the average $\mu$ of the maximum values of the monitored response parameters is reported together with the relevant coefficient of variation $\mathrm{CoV}$, i.e. the ratio between the standard deviation $(\sigma)$ and the average value. In order to highlight the effects of all the sources of nonlinearity characterizing the HDNR bearings behaviour, the results obtained by considering the HDNR model are compared with those obtained by considering the LVE reference model (with equivalent properties calibrated at the design conditions).

The results the ULS (reported in bold in the tables) are discussed first, since the reference LVE model has been calibrated at this intensity. With regards to the bearing deformation, the average value obtained by adopting the LVE reference model is almost equal to the design value $\left(\gamma_{b, d}=1.5\right)$ for case $a$, characterized by the most rigid superstructure $\left(T_{S}=0.25 \mathrm{~s}\right)$. A deviation from the design values is observed for the other cases, due to the larger deformability of the superstructure. In all the three cases, the average values obtained with the HDNR model are slightly lower, meaning that the third-cycle equivalent properties assumed for design purposes provides a slightly conservative bearing demand estimation. On the other hand, the HDNR model provides average values of superstructure accelerations larger than corresponding values obtained with the LVE model, confirming that the actual stiffness of the isolation system is larger than the equivalent one calibrated based on the third cycle data.

Table 5 - Mean value and coefficient of variation of isolator shear deformation $\gamma_{b}[-]$

\begin{tabular}{|c|c|c|c|c|c|c|c|c|c|c|c|c|}
\hline & \multicolumn{4}{|c|}{$T_{s}=0.25 \mathrm{~s}$} & \multicolumn{4}{|c|}{$T_{s}=0.50 \mathrm{~s}$} & \multicolumn{4}{|c|}{$T_{s}=1.00 \mathrm{~s}$} \\
\hline & \multicolumn{2}{|c|}{ HDNR } & \multicolumn{2}{|c|}{ LVE } & \multicolumn{2}{|c|}{ HDNR } & \multicolumn{2}{|c|}{ LVE } & \multicolumn{2}{|c|}{ HDNR } & \multicolumn{2}{|c|}{ LVE } \\
\hline & $\mu$ & $\mathrm{CoV}$ & $\mu$ & $\mathrm{CoV}$ & $\mu$ & $\mathrm{CoV}$ & $\mu$ & $\mathrm{CoV}$ & $\mu$ & $\mathrm{CoV}$ & $\mu$ & $\mathrm{CoV}$ \\
\hline OLS & 0.46 & $23 \%$ & 0.57 & & 0.46 & $22 \%$ & 0.57 & & 0,45 & $20 \%$ & 0,57 & \\
\hline DLS & 0.71 & $20 \%$ & 0.85 & $0 \%$ & 0.71 & $20 \%$ & 0.85 & $1 \%$ & 0,70 & $17 \%$ & 0,86 & $6 \%$ \\
\hline ULS & 1.44 & $14 \%$ & 1.50 & & 1.44 & $14 \%$ & 1.50 & & 1,39 & $11 \%$ & 1,51 & \\
\hline CLS & 1.95 & $9 \%$ & 1.92 & & 1.93 & $8 \%$ & 1.93 & & 1,85 & $7 \%$ & 1,94 & CLS \\
\hline
\end{tabular}

Table 6 - Mean value and coefficient of variation of floor absolute accelerations $\ddot{u}_{s}\left[\mathrm{~m} / \mathrm{s}^{2}\right]$

\begin{tabular}{|c|c|c|c|c|c|c|c|c|c|c|c|c|}
\hline & \multicolumn{4}{|c|}{$T_{s}=0.25 \mathrm{~s}$} & \multicolumn{4}{|c|}{$T_{s}=0.50 \mathrm{~s}$} & \multicolumn{4}{|c|}{$T_{s}=1.00 \mathrm{~s}$} \\
\hline & \multicolumn{2}{|c|}{ HDNR } & \multicolumn{2}{|c|}{ LVE } & \multicolumn{2}{|c|}{ HDNR } & \multicolumn{2}{|c|}{ LVE } & \multicolumn{2}{|c|}{ HDNR } & \multicolumn{2}{|c|}{ LVE } \\
\hline & $\mu$ & $\mathrm{CoV}$ & $\mu$ & $\mathrm{CoV}$ & $\mu$ & $\mathrm{CoV}$ & $\mu$ & $\mathrm{CoV}$ & $\mu$ & $\mathrm{CoV}$ & $\mu$ & $\mathrm{CoV}$ \\
\hline OLS & 0.70 & $18 \%$ & 0.54 & & 0.73 & $18 \%$ & 0.57 & & 0.80 & $19 \%$ & 0.60 & \\
\hline DLS & 0.92 & $17 \%$ & 0.81 & $3 \%$ & 0.97 & $17 \%$ & 0.85 & $6 \%$ & 1.07 & $19 \%$ & 0.89 & $9 \%$ \\
\hline ULS & 1.51 & $18 \%$ & 1.43 & & 1.62 & $21 \%$ & 1.50 & & 1.75 & $19 \%$ & 1.57 & \\
\hline
\end{tabular}

Table 7 - Mean value and coefficient of variation of superstructure relative displacement $v_{s}$ [cm]

\begin{tabular}{|c|c|c|c|c|c|c|c|c|c|c|c|c|}
\hline & \multicolumn{4}{|c|}{$T_{s}=0.25 \mathrm{~s}$} & \multicolumn{4}{|c|}{$T_{s}=0.50 \mathrm{~s}$} & \multicolumn{4}{|c|}{$T_{s}=1.00 \mathrm{~s}$} \\
\hline & \multicolumn{2}{|c|}{ HDNR } & \multicolumn{2}{|c|}{ LVE } & \multicolumn{2}{|c|}{ HDNR } & \multicolumn{2}{|c|}{ LVE } & \multicolumn{2}{|c|}{ HDNR } & \multicolumn{2}{|c|}{ LVE } \\
\hline & $\mu$ & $\mathrm{CoV}$ & $\mu$ & $\mathrm{CoV}$ & $\mu$ & $\mathrm{CoV}$ & $\mu$ & $\mathrm{CoV}$ & $\mu$ & $\mathrm{CoV}$ & $\mu$ & $\mathrm{CoV}$ \\
\hline OLS & 0.11 & $18 \%$ & 0.09 & $3 \%$ & 0.46 & $18 \%$ & 0.36 & $6 \%$ & 2.02 & $19 \%$ & 1.51 & $9 \%$ \\
\hline
\end{tabular}




\begin{tabular}{lllllllllll} 
DLS & 0.15 & $17 \%$ & 0.13 & 0.61 & $17 \%$ & 0.54 & 2.71 & $19 \%$ & 2.26 \\
ULS & $\mathbf{0 . 2 4}$ & $\mathbf{1 8 \%}$ & $\mathbf{0 . 2 3}$ & $\mathbf{1 . 0 3}$ & $\mathbf{2 1 \%}$ & $\mathbf{0 . 9 5}$ & $\mathbf{4 . 4 2}$ & $\mathbf{1 9 \%}$ & $\mathbf{3 . 9 7}$ \\
\hline
\end{tabular}

For the other limit states, the LVE model provides, as expected, results that vary linearly with the seismic intensity. It is noted that at the CLS limit state intensity level, only results in terms of the bearings deformation are reported, according to code requirements [15],[16]. Results obtained with the HDNR model are slightly lower in terms of bearing deformation for frequent events, whereas they are similar in terms of bearing deformation and larger in terms of superstructure response for the CLS. This is because, as shown in Figure 3, the HDNR model is stiffer and more dissipative for shear deformations lower than the design one, and stiffer but less dissipative for shear deformations larger than the design one.

Previous results are summarized in Figure 5, showing mean values of the response parameters of interest obtained with the HDNR and the LVE reference model, normalized with respect to the mean values of LVE reference model, for the different seismic intensity levels. In particular, from Figure 5a to Figure 5c trends of the superstructure absolute acceleration and relative displacement are reported. It should be noted that these trends are practically coincident because, as resulting from Eq. $2 \mathrm{~b}$ or $3 \mathrm{~b}$, for small values of the superstructure damping $\left(\xi_{s}\right)$ the ratio between the two response parameters is almost equal to the superstructure circular frequency $\left(\omega_{s}\right)$. Figure $5 \mathrm{~d}-\mathrm{f}$ shows the trends of the normalized bearings deformation. These plots confirms that, in terms of mean values, the consequence of the nonlinear behavior of HDNR bearings including stress softening are limited at all the considered hazard levels and for all the case analyzed. However, significant differences are obtained in term of response variation, as shown in Figure 5 in terms of the $16^{\text {th }}$ and $84^{\text {th }}$ percentiles of the normalized response parameters considered. In general the response dispersion is notably larger in the case of the HDNR model compared to the case of the LVE model for all the cases analysed and response parameters of interest. In particular, due to the selected intensity measure and the procedure used to scale the records, in the case of the LVE model and very rigid superstructure (case $a$ ), the dispersion of the bearing shear strain is almost zero. The dispersion slightly increases by passing from a rigid to a flexible superstructure, because of the increasing effect of the second mode of vibration. Differently, by adopting the HDNR model, the nonlinear behaviour and transient response (i.e. the first response cycles affected by stresssoftening) strongly affects the dynamic response of the isolated system, leading to a significantly larger dispersion of all the response parameters.
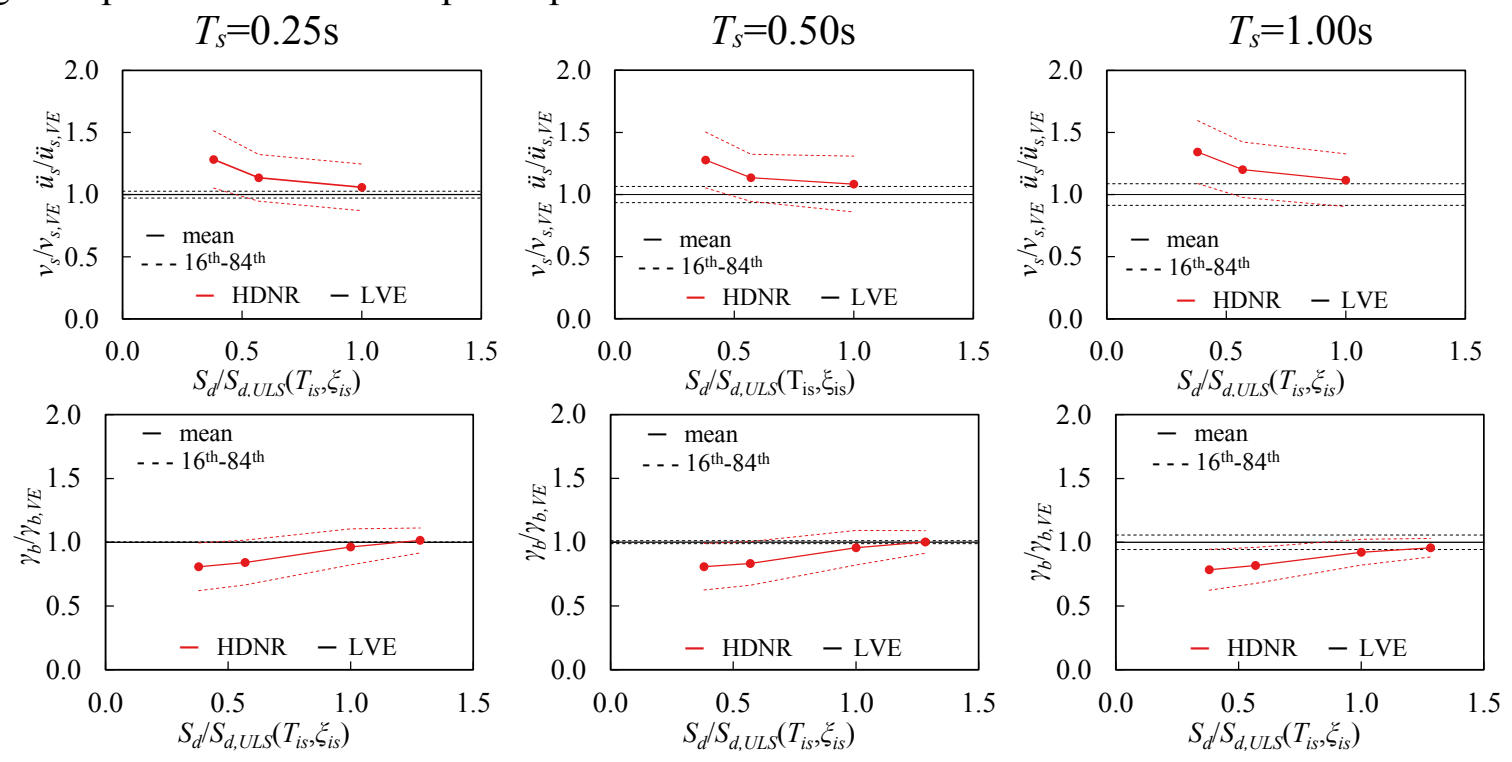


\section{Figure 5 - Mean and $16^{\text {th }}-84^{\text {th }}$ percentiles of normalized response parameters: $(a, b, c)$ superstructure relative displacements and absolute accelerations; (d,e,f) shear strain of bearings.}

In order to better understand the influence of the HDNR behaviour on the dynamic response of isolated systems, Figure 6 illustrates the hysteretic response of the bearings for the intermediate case with $T_{S}=0.5 \mathrm{~s}$, under the records yielding the minimum, the average and the maximum shear deformation of the bearings at the ULS intensity level (record \#17, \#16 and \#6 respectively). The cycles obtained with the reference LVE model are also plotted in the same figure. The comparison shows that the stiffness of the HDNR model is usually larger than the reference LVE stiffness, leading to an isolation period different from the design one and thus a seismic demand different from the design value.
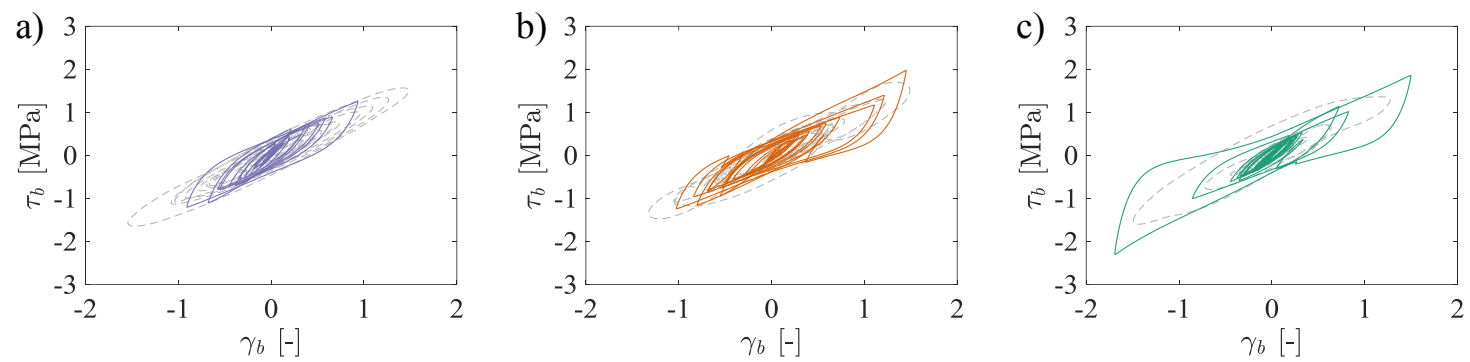

Figure 6 - Hysteresis loops for HDNR and LVE models at the ULS intensity level for records (a) \#17, (b) \#16 and (c) \#6.

Finally, in order to investigate the seismic performance of equipment and building contents linked to superstructure by deformable connections, $5 \%$ damped floor response spectra (FRS) have been computed as mean values at each period of the top mass spectral accelerations given by the different records. Figure 7 shows the FRS obtained for different limit states by considering a rigid superstructure as well as the three flexible superstructures analysed in the parametric study. Usually, functionality is required at serviceability limit states, however, for completeness, FRS at the ULS are also evaluated and discussed. Here again, the FRS obtained by adopting the HDNR model is compared with the corresponding FRS obtained by using the LVE reference model. With regards to the case of rigid superstructure (Figure 7a), as expected, the mean FRS obtained with the LVE bearing model exhibits a single peak in correspondence of the design isolation period $\left(T_{i s}=2.5 \mathrm{sec}\right)$ for all the seismic intensities considered. The mean FRS obtained with the HDNR model also exhibits a single peak, but changing in shape, amplitude and location with the seismic intensity level, due to all sources of nonlinearity affecting the HDNR behaviour. In particular, for the ULS level, the peak is lower in amplitude compared to the LVE case, but it is wider (ranging from periods of $2 \mathrm{~s}$ to $2.5 \mathrm{~s}$ ). This again is due to the nonlinear behaviour of HDNR bearings, also affected by stress softening, which causes a record-dependent response of the isolated system. For the OLS and the DLS intensity levels, the peaks of the two models are more similar in amplitude and shape, but those obtained with the HDNR model are shifted towards lower periods of vibration, confirming the higher rubber stiffness for small strain amplitudes and the less remarkable recorddependent response.

For the systems with a flexible superstructure, the mean FRS (plotted in Figure 7b-d) shows multiple peaks due to the contribution of the second mode of vibration of the isolated system, which is more and more important as the superstructure period and the seismic intensity increase. However, this contribution is almost negligible in the case of the LVE bearing model, whereas it is very significant for the case of HDNR bearing model. Also in this case, the obtained differences 
are due to the complex nonlinear HDNR behaviour, which significantly excites the higher vibration mode of the isolated systems. However, for serviceability limit states, the secondary peak remains notably lower than the primary one. Only in the case of very flexible structure (case $c$ ) at ULS, the peak in correspondence of the second period is similar to the peak in correspondence of the first one.
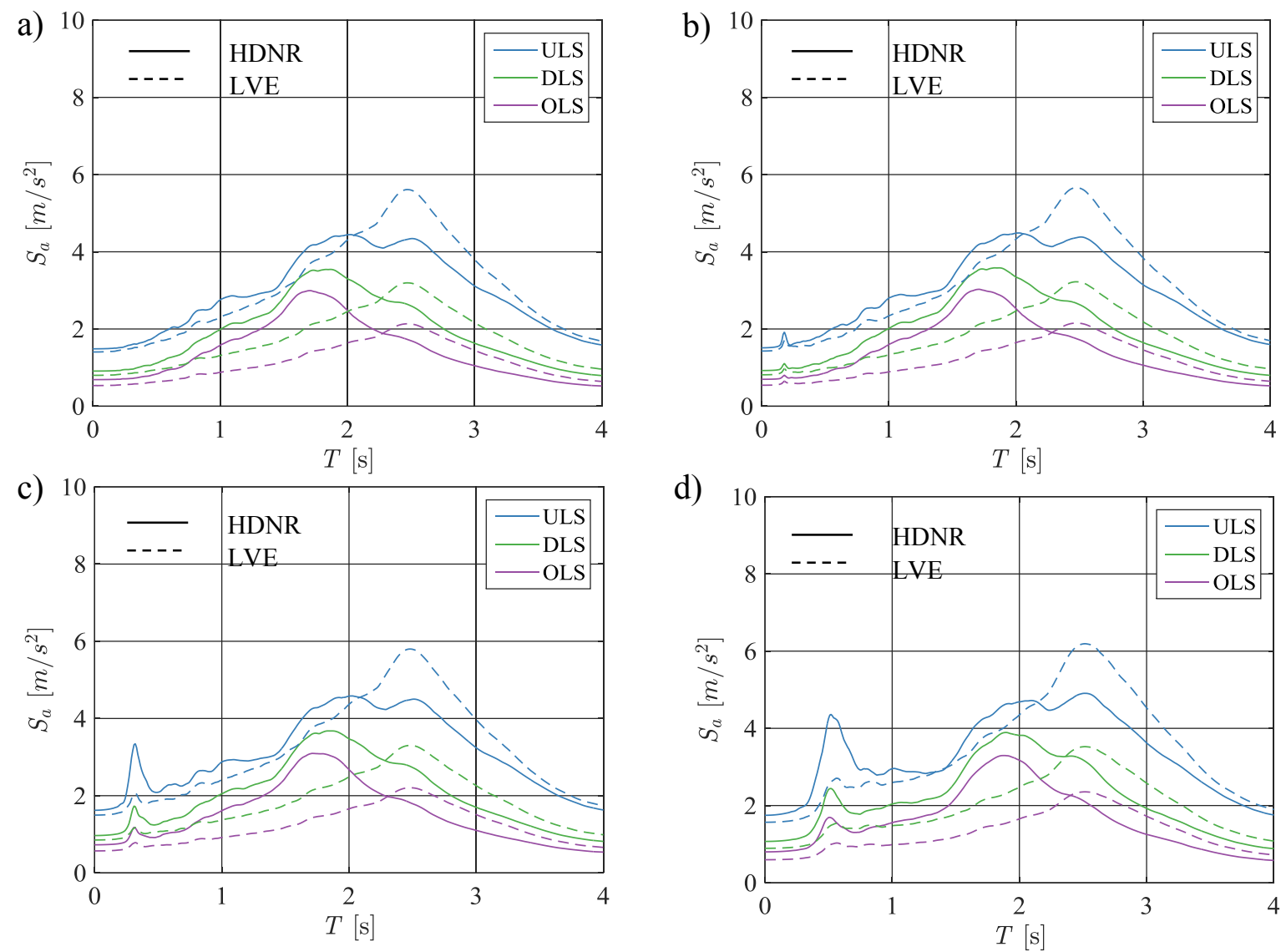

Figure 7 - Floor response spectra (FRS) for (a) the case with rigid superstructure and flexible superstructure with (b) $T s=0.25 \mathrm{~s}$, (c) $T s=0.50 \mathrm{~s}$, and (d) $\mathrm{Ts}=1.0 \mathrm{~s}$.

\section{SEIMIC RESPONSE OF AN ISOLATED BUILDING}

In this section, a realistic case study, consisting in a M-DOF system, is considered to investigate the response at various floor levels and to evaluate the influence of the superior modes. Moreover, other aspects characterizing the performance of real applications are investigated, such as the influence of the superstructure damping and the friction of sliders commonly employed together with HDNR bearings to form a hybrid isolation system.

\section{Case study design and modal analysis}

The case study consists in a 6-storey three-dimensional reinforced concrete building frame (Figure 8 ). The beams and columns have a rectangular transverse cross section with height of $500 \mathrm{~mm}$ and width of $300 \mathrm{~mm}$. The floors are assumed rigid in plane and have a mass of $200 \mathrm{kNms}^{-1}$. A hybrid isolation system, consisting of 6 HDNR bearings and 9 low friction flat sliders providing mainly a vertical support (Figure 8), is considered. 

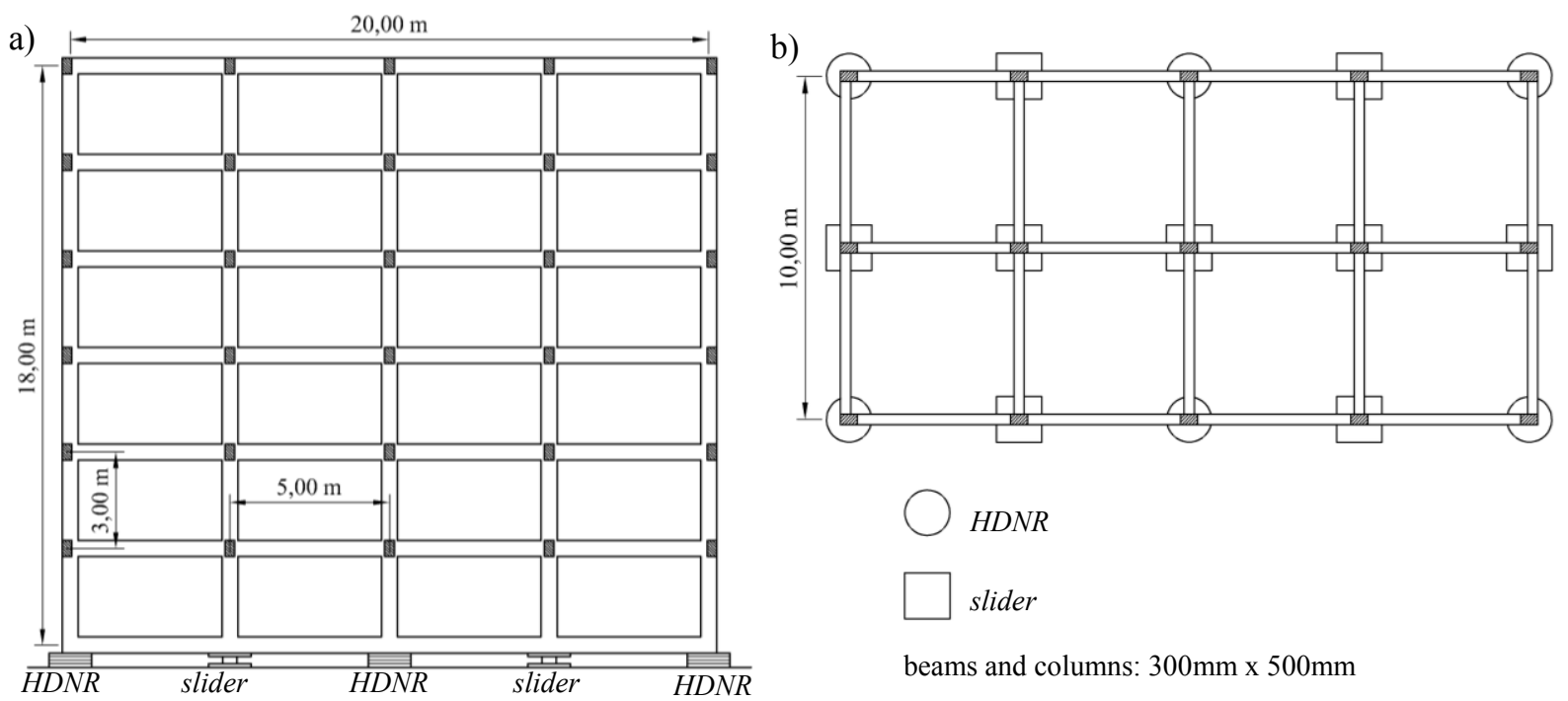

Figure 8 - (a) 6-storeys isolated building, and (b) isolation system configuration.

The design of the isolators is carried out by assuming the superstructure as rigid and by considering the same target period of vibration as for the 2-DOF systems $\left(T_{i s, d}=2.5 \mathrm{~s}\right)$. Assuming zero friction of the sliders, the same design action and the same design shear strain of the bearings $\left(\gamma_{b, d}=1.5\right)$ of the 2-DOF of systems, the design leads to $6 \mathrm{HNDR}$ bearings with diameter $D_{i s}=504 \mathrm{~mm}$ and total rubber thickness equal to $t_{r}=h_{i s}=138 \mathrm{~mm}$. The secondary shape factor $S_{2}=D / t_{r}$ is equal to 3.6. The bearings are obtained by combining 20 rubber layers of thickness $t_{s}=6.9 \mathrm{~mm}$ and the primary shape factor $S_{1}=D / 4 t_{\mathrm{s}}$ is 18.3 . By this way, bearings agree with indications about primary and secondary shape factors given by the technical literature and the standard for buildings isolation [26],[38]. It is noteworthy that choice of employing this hybrid isolation system yields large isolators with an ample margin with respect to the buckling load capacity. In fact, according to the European code on anti-seismic devices [13], when the maximum axial load is smaller than the ratio $P_{c r} / 4$ (where $P_{c r}$ is buckling load capacity of the bearings at zero displacement according to [13]) the buckling is prevented if the horizontal displacement is smaller than $0.7 \cdot D_{i s}$. In this case, $0.7 \cdot D_{i s}=0.353 \mathrm{~m}$ and $P_{c r} / 4=4405 \mathrm{kN}$, whereas the design displacement at the CLS is about $0.207 \mathrm{~m}$ and the axial forces due to vertical loads are about $830 \mathrm{kN}$ and $440 \mathrm{kN}$ for central and lateral bearings respectively.

Also in the case of M-DOF system, by using the LVE model of the bearings and by assuming zero friction of the sliders, the M-DOF system becomes a linear system. Thus, a complex modal analysis can be carried out on the linear finite element model of the M-DOF system to evaluate the modal properties and verify the design, as already done for the 2-DOF systems. In particular, the model of the superstructure is built by considering a Young modulus of concrete equal to $32000 \mathrm{MPa}$ and a cracking reduction coefficient equal to 0.5 for the beams and 0.7 for the columns of the superstructure. Moreover, as for the 2-DOF systems, a stiffness proportional damping is assumed, whereas the mass-proportional component is set equal to zero because it would lead to underestimate the isolated system response [33]. The damping constant for the stiffnessproportional damping matrix is calibrated to provide a damping ratio equal to $2 \%$ in correspondence of the first vibration period of the fixed-base superstructure. Figure 9 illustrates the absolute values of the undamped eignenmodes of the first three vibration modes of the isolated M-DOF system with the LVE model of bearings calibrated at the design conditions $\left(\gamma_{b, d}=1.5,3^{\text {rd }}\right.$ cycle of imposed deformation history). The relevant mass participation ratios are $0.995,0.004$ and 0.0002 respectively. 


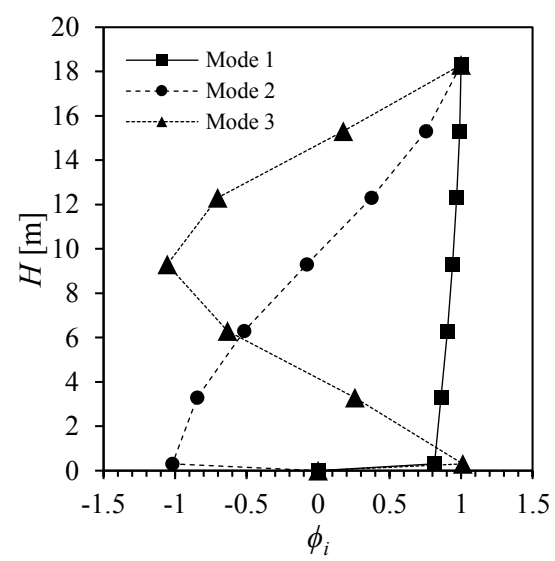

Figure 9 - First three modal shapes of the isolated M-DOF system for the LVE bearing model corresponding to the design condition $\left(\gamma_{b, d}=1.5,3^{\text {rd }}\right.$ cycle $)$.

Table 8 - Modal analysis results M-DOF

\begin{tabular}{|c|c|c|c|c|c|c|c|c|c|c|c|c|}
\hline \multirow[b]{2}{*}{$\begin{array}{c}\gamma \\
{[-]}\end{array}$} & \multicolumn{4}{|c|}{$1^{\text {st }}$ cycle } & \multicolumn{4}{|c|}{$3^{\text {rd }}$ cycle } & \multicolumn{4}{|c|}{$10^{\text {th }}$ cycle } \\
\hline & $\begin{array}{c}T_{1} \\
{[\mathrm{~s}]}\end{array}$ & $\begin{array}{c}\xi_{1} \\
{[-]}\end{array}$ & $\begin{array}{c}T_{2} \\
{[\mathrm{~s}]}\end{array}$ & $\begin{array}{c}\xi_{2} \\
{[-]}\end{array}$ & $\begin{array}{c}T_{l} \\
{[\mathrm{~s}]}\end{array}$ & $\begin{array}{c}\xi_{1} \\
{[-]}\end{array}$ & $\begin{array}{c}T_{2} \\
{[\mathrm{~s}]}\end{array}$ & $\begin{array}{c}\xi_{2} \\
{[-]}\end{array}$ & $\begin{array}{l}T_{1} \\
{[\mathrm{~s}]}\end{array}$ & $\begin{array}{c}\xi_{1} \\
{[-]}\end{array}$ & $\begin{array}{c}T_{2} \\
{[\mathrm{~s}]}\end{array}$ & $\begin{array}{c}\xi_{2} \\
{[-]}\end{array}$ \\
\hline $300 \%$ & 1.76 & $4.7 \%$ & 0.51 & $7.8 \%$ & 2.11 & $4.8 \%$ & 0.53 & $6.6 \%$ & 2.36 & $4.6 \%$ & 0.54 & $6.0 \%$ \\
\hline $250 \%$ & 2.03 & $7.6 \%$ & 0.52 & $9.1 \%$ & 2.42 & $7.8 \%$ & 0.54 & $7.8 \%$ & 2.70 & $7.6 \%$ & 0.55 & $7.0 \%$ \\
\hline $200 \%$ & 2.26 & $10.8 \%$ & 0.53 & $10.3 \%$ & 2.64 & $11.1 \%$ & 0.55 & $9.0 \%$ & 2.95 & $11.0 \%$ & 0.55 & $8.1 \%$ \\
\hline $150 \%$ & 2.35 & $12.7 \%$ & 0.54 & $11.1 \%$ & 2.65 & $13.4 \%$ & 0.55 & $10.1 \%$ & 2.94 & $13.4 \%$ & 0.55 & $9.2 \%$ \\
\hline $100 \%$ & 2.28 & $13.0 \%$ & 0.54 & $11.6 \%$ & 2.47 & $14.1 \%$ & 0.54 & $11.3 \%$ & 2.70 & $14.3 \%$ & 0.55 & $10.4 \%$ \\
\hline $75 \%$ & 2.20 & $12.5 \%$ & 0.53 & $11.7 \%$ & 2.32 & $13.9 \%$ & 0.54 & $11.9 \%$ & 2.51 & $14.2 \%$ & 0.54 & $11.1 \%$ \\
\hline $50 \%$ & 2.08 & $11.1 \%$ & 0.53 & $11.5 \%$ & 2.14 & $12.5 \%$ & 0.53 & $12.2 \%$ & 2.27 & $12.8 \%$ & 0.54 & $11.5 \%$ \\
\hline
\end{tabular}

Table 8 reports the vibration period and damping ratio of the first two modes, for LVE models calibrated at different shear deformations and different cycles, with values at the design conditions highlighted in bold. As for the case of the 2-DOF model, the difference between the target isolation period and the actual period $T_{1}$ is not very significant and it is mainly due to the influence of the superstructure flexibility.

\section{Equivalent 2-DOF system and seismic response estimation}

In this section, results obtained in the parametric analysis involving 2-DOF systems and illustrated in the previous section are used to estimate the response of the M-DOF system. To this purpose, the procedure to reduce the isolated M-DOF system to the equivalent 2-DOF system is illustrated, following the indications given in [2]. In particular, the first period of the fixed-based superstructure $\left(T_{1, f i x}\right)$ must be equal to the superstructure fixed-base fundamental period of the 2DOF system $\left(T_{s}\right)$. Moreover, the the effective mass of the first mode of the fixed-base superstructure $\left(M_{\text {eff, } 1, f i x}\right)$ must be equal to top mass of the 2-DOF system $(m)$. To this purpose, the mass ratio already defined in Eq. 4 for the 2-DOF system, must be equal to the mass ratio of the M-DOF, which can be expressed as follows:

$\rho=\frac{L_{1, f i x}^{2} M_{1, f i x}}{M}=\frac{M_{e f f, 1, f i x}}{M}$ 
where $M$ is the total mass of the building, $M_{1, f i x}$ is the modal mass of the first mode of the fixedbase superstructure, and $L_{1, f i x}$ is the first mode participation factor. The modal analysis carried out on the fixed-base superstructure of the case study illustrated in Figure 8 gives a fixed-base fundamental period and a mass ratio matching those of case $c$ of the 2-DOF systems analysed in the previous section $\left(T_{1, f i x}=T_{s}=1 \mathrm{~s}\right.$ and $\left.\rho=0.7\right)$. The "equivalence" is also confirmed by the good agreement between the period and damping ratio reported in Table 8 (for the M-DOF system) and in Table 2 (for the 2-DOF system) for both the $1^{\text {st }}$ and $2^{\text {nd }}$ mode. Thus, this "equivalent" 2-DOF system can provide an approximation of the response of the M-DOF isolated system, accounting only for the contribution of the first mode of the superstructure. In particular, as illustrated in [2], knowing the relative displacement $v_{\mathrm{s}}$ of the top mass of the 2-DOF equivalent system with respect to the base mass, the M-DOF superstructure displacement response at the $i$-th floor can be obtained through the following relation:

$v_{s 1, i}(t)=\phi_{1, i, f i x} L_{1, f i x} v_{s}(t)$

where $v_{s 1, i}$ (for $i=1,2, . ., 6$ ) are the relative displacements of the superstructure floors with respect to the isolation system due to the first mode, $\phi_{1, i, f i x}$ are the modal displacements of the fixed-base fundamental mode reported in Table 9. It is noted that the value of the modal product $L_{1, f i x} \cdot \phi_{1, i, f i x}$ is close to one at the 4-th floor of the building, meaning that results of the 2-DOF system obtained in the previous section are representative of response of the M-DOF approximately at the 4-th floor. The superstructure floor absolute accelerations can be also estimated through the following expression:

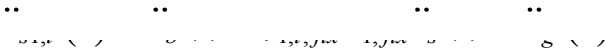

The estimates of average values of the maximum floor relative displacements and maximum absolute accelerations obtained by using results of the analyses carried out on the equivalent 2DOF system ( $\operatorname{case} c$ ) and Eqs. 12 and 13 are reported in Table 10 for the different seismic intensities considered.

Table 9 - Modal displacements of the fixed-base fundamental mode.

\begin{tabular}{cccccc}
$L_{1, f i x} \phi_{1,1, f i x}$ & $L_{1, f i x} \phi_{1,2, f i x}$ & $L_{1, f i x} \phi_{1,3, f i x}$ & $L_{1, f i x} \phi_{1,4, f i x}$ & $L_{1, f i x} \phi_{1,5, f i x}$ & $L_{1, f i x} \phi_{1,6, f i x}$ \\
\hline 0.257 & 0.545 & 0.808 & 1.025 & 1.181 & 1.273
\end{tabular}

Table 10 - Estimates of maximum floor relative displacements and absolute accelerations.

\begin{tabular}{cccccccccccccc}
\hline \multicolumn{1}{c}{ relative floor displacements } & \multicolumn{4}{c}{ absolute floor accelerations } \\
\hline & $v_{s 1,1}$ & $v_{s 2,2}$ & $v_{s 1,3}$ & $v_{s 1,4}$ & $v_{s 1,5}$ & $v_{s 1,6}$ & $\ddot{u}_{b}$ & $\ddot{u}_{s 1,1}$ & $\ddot{u}_{s 1,2}$ & $\ddot{u}_{s 1,3}$ & $\ddot{u}_{s 1,4}$ & $\ddot{u}_{s 1,5}$ & $\ddot{u}_{s 1,6}$ \\
& {$[\mathrm{~cm}]$} & {$[\mathrm{cm}]$} & {$[\mathrm{cm}]$} & {$[\mathrm{cm}]$} & {$[\mathrm{cm}]$} & {$[\mathrm{cm}]$} & {$\left[\mathrm{m} / \mathrm{s}^{2}\right]$} & {$\left[\mathrm{m} / \mathrm{s}^{2}\right]$} & {$\left[\mathrm{m} / \mathrm{s}^{2}\right]$} & {$\left[\mathrm{m} / \mathrm{s}^{2}\right]$} & {$\left[\mathrm{m} / \mathrm{s}^{2}\right]$} & {$\left[\mathrm{m} / \mathrm{s}^{2}\right]$} & {$\left[\mathrm{m} / \mathrm{s}^{2}\right]$} \\
\hline OLS & 0.5 & 1.1 & 1.6 & 2.1 & 2.4 & 2.6 & 0.93 & 0.80 & 0.70 & 0.71 & 0.82 & 0.92 & 0.98 \\
DLS & 0.7 & 1.5 & 2.2 & 2.8 & 3.2 & 3.5 & 1.30 & 1.10 & 0.92 & 0.93 & 1.09 & 1.25 & 1.35 \\
ULS & $\mathbf{1 . 1}$ & $\mathbf{2 . 4}$ & $\mathbf{3 . 6}$ & $\mathbf{4 . 5}$ & $\mathbf{5 . 2}$ & $\mathbf{5 . 6}$ & $\mathbf{2 . 3 0}$ & $\mathbf{1 . 8 7}$ & $\mathbf{1 . 5 0}$ & $\mathbf{1 . 4 9}$ & $\mathbf{1 . 7 9}$ & $\mathbf{2 . 1 1}$ & $\mathbf{2 . 3 1}$ \\
\hline
\end{tabular}

Seismic performance at serviceability and design limit states

This section summarizes the results of the analyses of the isolated M-DOF system carried out at different hazard levels. The analyses have been performed by considering the advanced HDNR material model with stress-softening for the bearings, whereas the shear forces of the flat sliders due to friction or a possible rubber layer below the sliders have been neglected. Table 11 reports average values $\mu$ and coefficients of variation $\mathrm{CoV}$ of the maximum response in terms of shear deformation of bearings $\gamma_{b}$ and the superstructure relative displacements $v_{s, i}$ of the $i$-floor with 
respect to the base floor. The values of the superstructure inter-storey drifts $d_{s, i}$ and the absolute floor accelerations $\ddot{u}_{s, i}$ are also reported in Table 12 and Table 13 respectively. Also in this case, the CLS intensity level is considered only for the deformation of bearings, as required by seismic codes [15],[16].

Table 11 - Bearings shear deformation $\gamma_{b}[-]$ and superstructure relative floor displacements $v_{s, i}[\mathrm{~cm}]$

\begin{tabular}{|c|c|c|c|c|c|c|c|c|c|c|c|c|c|c|}
\hline & \multicolumn{2}{|c|}{$\gamma_{b}$} & \multicolumn{2}{|c|}{$v_{s, 1}$} & \multicolumn{2}{|c|}{$v_{s, 2}$} & \multicolumn{2}{|c|}{$v_{s, 3}$} & \multicolumn{2}{|c|}{$v_{s, 4}$} & \multicolumn{2}{|c|}{$v_{s, 5}$} & \multicolumn{2}{|c|}{$v_{s, 6}$} \\
\hline & $\mu$ & $\mathrm{CoV}$ & $\mu$ & $\mathrm{CoV}$ & $\mu$ & $\mathrm{CoV}$ & $\mu$ & $\mathrm{CoV}$ & $\mu$ & $\mathrm{CoV}$ & $\mu$ & $\mathrm{CoV}$ & $\mu$ & $\mathrm{CoV}$ \\
\hline OLS & 0.45 & $19 \%$ & 0.6 & $15 \%$ & 1.2 & $16 \%$ & 1.8 & $17 \%$ & 2.2 & $17 \%$ & 2.5 & $18 \%$ & 2.7 & $18 \%$ \\
\hline DLS & 0.70 & $17 \%$ & 0.8 & $14 \%$ & 1.6 & $14 \%$ & 2.4 & $15 \%$ & 3.0 & $16 \%$ & 3.4 & $17 \%$ & 3.7 & $17 \%$ \\
\hline ULS & 1.39 & $10 \%$ & 1.3 & $13 \%$ & 2.6 & $14 \%$ & 3.8 & $15 \%$ & 4.8 & $16 \%$ & 5.5 & $17 \%$ & 6.0 & $17 \%$ \\
\hline CLS & 1.85 & $7 \%$ & 1.7 & $13 \%$ & 3.5 & $14 \%$ & 5.1 & $15 \%$ & 6.5 & $16 \%$ & 7.5 & $17 \%$ & 8.1 & $17 \%$ \\
\hline
\end{tabular}

Table 12 - Superstructure inter-storey drifts $d_{s, i}[-]$

\begin{tabular}{|c|c|c|c|c|c|c|c|c|c|c|c|c|}
\hline & \multicolumn{2}{|c|}{$d_{s, 1}$} & \multicolumn{2}{|c|}{$d_{s, 2}$} & \multicolumn{2}{|c|}{$d_{s, 3}$} & \multicolumn{2}{|c|}{$d_{s, 4}$} & \multicolumn{2}{|c|}{$d_{s, 5}$} & \multicolumn{2}{|c|}{$d_{s, 6}$} \\
\hline & $\mu$ & $\mathrm{CoV}$ & $\mu$ & $\mathrm{CoV}$ & $\mu$ & $\mathrm{CoV}$ & $\mu$ & $\mathrm{CoV}$ & $\mu$ & $\mathrm{CoV}$ & $\mu$ & $\mathrm{CoV}$ \\
\hline OLS & $0.2 \%$ & $15 \%$ & $0.2 \%$ & $17 \%$ & $0.2 \%$ & $18 \%$ & $0.2 \%$ & $20 \%$ & $0.1 \%$ & $21 \%$ & $0.1 \%$ & $21 \%$ \\
\hline DLS & $0.3 \%$ & $14 \%$ & $0.3 \%$ & $15 \%$ & $0.2 \%$ & $18 \%$ & $0.2 \%$ & $21 \%$ & $0.2 \%$ & $22 \%$ & $0.1 \%$ & $21 \%$ \\
\hline ULS & $0.4 \%$ & $13 \%$ & $0.4 \%$ & $15 \%$ & $0.4 \%$ & $18 \%$ & $0.3 \%$ & $21 \%$ & $0.3 \%$ & $22 \%$ & $0.2 \%$ & $22 \%$ \\
\hline
\end{tabular}

Table 13 - Base floor acceleration $\ddot{u}_{b}\left[\mathrm{~m} / \mathrm{s}^{2}\right]$ and superstructure floor accelerations $\ddot{\boldsymbol{u}}_{s, i}\left[\mathrm{~m} / \mathrm{s}^{2}\right]$

\begin{tabular}{|c|c|c|c|c|c|c|c|c|c|c|c|c|c|c|}
\hline & \multicolumn{2}{|c|}{$\ddot{u}_{b}$} & \multicolumn{2}{|c|}{$\ddot{u}_{s, 1}$} & \multicolumn{2}{|c|}{$\ddot{u}_{s, 2}$} & \multicolumn{2}{|c|}{$\ddot{u}_{s, 3}$} & \multicolumn{2}{|c|}{$\ddot{u}_{s, 4}$} & \multicolumn{2}{|c|}{$\ddot{u}_{s, 5}$} & \multicolumn{2}{|c|}{$\ddot{u}_{s, 6}$} \\
\hline & $\mu$ & $\mathrm{CoV}$ & $\mu$ & $\mathrm{CoV}$ & $\mu$ & $\mathrm{CoV}$ & $\mu$ & $\mathrm{CoV}$ & $\mu$ & $\mathrm{CoV}$ & $\mu$ & $\mathrm{CoV}$ & $\mu$ & $\mathrm{CoV}$ \\
\hline OLS & 0.87 & $25 \%$ & 0.83 & $23 \%$ & 0.78 & $21 \%$ & 0.72 & $16 \%$ & 0.79 & $18 \%$ & 0.92 & $21 \%$ & 1.02 & $23 \%$ \\
\hline DLS & 1.19 & $25 \%$ & 1.13 & $24 \%$ & 1.03 & $21 \%$ & 0.95 & $16 \%$ & 1.06 & $17 \%$ & 1.25 & $22 \%$ & 1.41 & $23 \%$ \\
\hline ULS & 2.05 & $23 \%$ & 1.92 & $20 \%$ & 1.69 & $18 \%$ & 1.52 & $16 \%$ & 1.69 & $16 \%$ & 2.10 & $22 \%$ & 2.42 & $23 \%$ \\
\hline
\end{tabular}

With reference to the performance of the isolation system, average values of the bearings shear deformation are practically equal to the corresponding value obtained with the equivalent 2-DOF system for all the limit states considered, confirming the null influence of the modes higher than the second one on this response parameter and, in general, the ability of the isolation system to undergoes seismic actions up to the CLS. With regards to the superstructure, by comparing the obtained results with those reported in Table 10, it can be observed that the relative displacements and absolute accelerations may be quite accurately estimated by applying Eqs. 12 and 13. Thus, the influence of modes higher than the second one is very limited, as also observed in [39] for some cases of building frame isolated with CCS bearings. In particular, floor relative displacements increase with the building height, but accompanied by decreasing inter-storey drifts. Differently, floor absolute accelerations are larger at the base and top floors, due to the significant influence of the second mode of vibration of the isolated building, whose shape is illustrated in Figure 9. Maximum values of the inter-storey drifts, attained at the first storey, are respectively $0.2 \%$ and $0.3 \%$ for the OLS and DLS intensity levels and maximum values of the accelerations, attained at the top floor, are respectively $1.02 \mathrm{~m} / \mathrm{s}^{2}$ and $1.41 \mathrm{~m} / \mathrm{s}^{2}$. At the design limit state intensity level, the maximum absolute acceleration is $2.42 \mathrm{~m} / \mathrm{s}^{2}$ and the maximum inter-storey drift is $0.4 \%$, which is still lower than the limit imposed by the Eurocode 8 [27] for the limitation of damages of non-structural components, i.e. $0.5 \%$. This last result also confirms that the structure behaves elastically up to the design limit state, allowing the use of the elastic model for the superstructure. 
Mean FRS are also evaluated for all the building storeys and the ULS and the two serviceability limit states. Figure 10a illustrates the mean FRS at the ULS intensity level for each floor, whereas Figure 10b illustrates the mean FRS of the top floor for different seismic intensities. Similarly to the case of the equivalent 2-DOF system, two major peaks are observed, in correspondence of the first and second vibration period of the isolated system. However, it is interesting to observe that the first mode peak slightly increases by passing from the base to the top floor. Differently, in correspondence of the second mode, the peaks of the base and top floors and also of the $1^{\text {th }}$ and $5^{\text {th }}$ floors are larger than the peaks of the $2^{\text {th }}$ and $4^{\text {th }}$ floors. This is consistent with the shape of the second mode (Figure 9), resulting in different demands at various floors. For the same reason, the $3^{\text {th }}$ floor does not exhibit a peak in correspondence of the second vibration period, since it is located in correspondence of the node of the modal shape (see Figure 9). It is also worth to note that, as shown in Figure 10b referring to the top floor, for serviceability limit states (OLS and DLS) the peak in correspondence of the second vibration period is similar in amplitude to the peak in correspondence of the first vibration mode and becomes significantly larger for seismic actions equal to the design one.
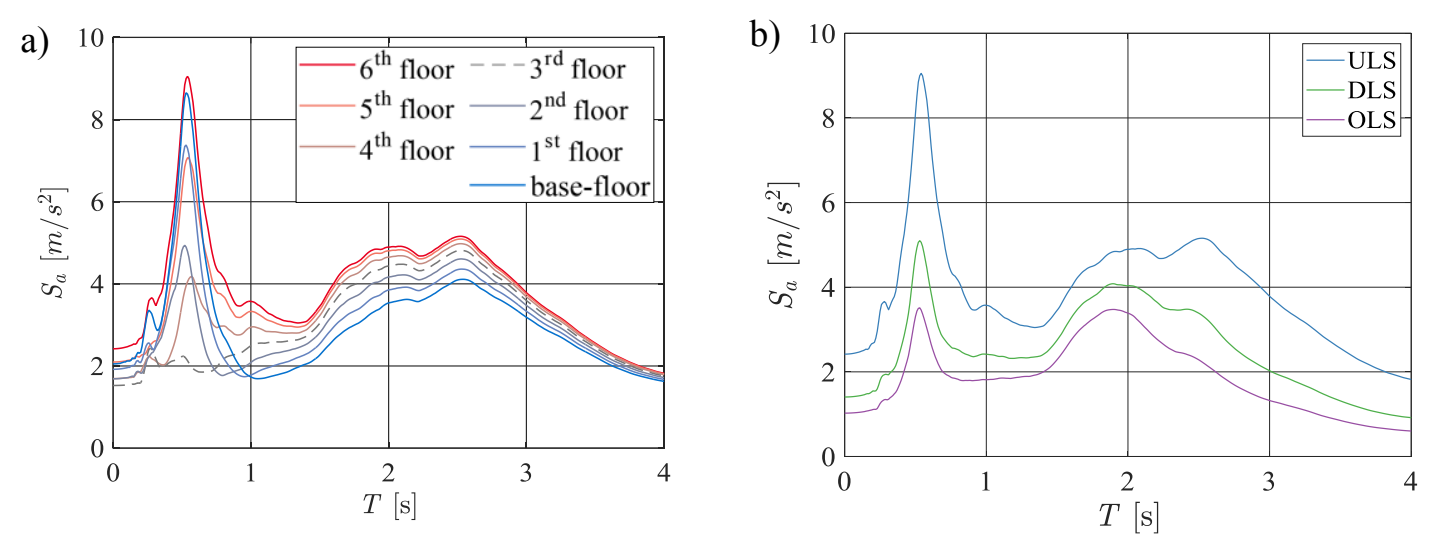

\section{Figure 10 - FRS of (a) superstructure floors at the ULS and (b) the top floor for different limit states.}

To further investigate this issue, Figure 11 plots the acceleration transfer functions, evaluated similarly to [40] as the ratio of the Fourier spectra of the $i$-floor acceleration to the Fourier spectra of the ground acceleration. Similarly to the case of the FRS, the transfer functions are computed at each period as the mean of the transfer functions obtained for the set of records considered..

a)

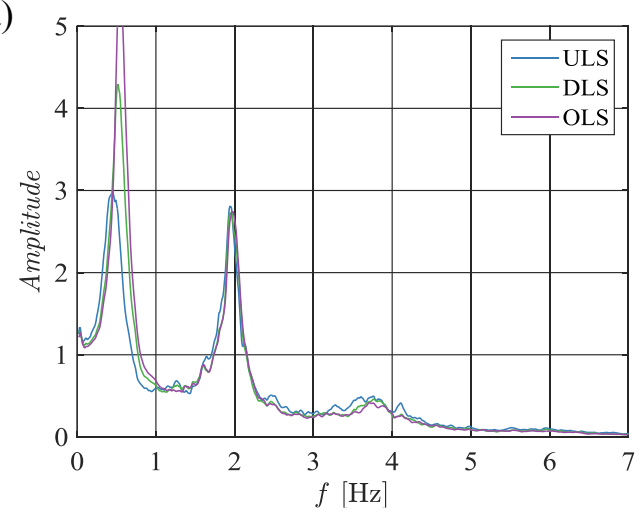

b)

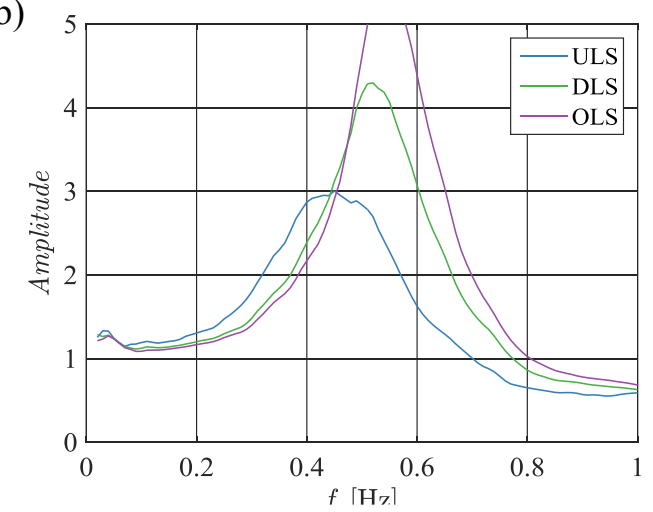

Figure 11- (a) Amplitude of the Fourier transform of top-floor absolute accelerations at different limit states and (b) zoom on the peak corresponding to the first mode. 
These functions allow to highlight the acceleration response amplifications in correspondence of the first and second vibration periods It can be observed that the peak in correspondence of the first mode is higher than that of the second mode, and its amplitude reduces and shifts to lower frequencies for increasing earthquake intensities (Figure 11b). On the other hand, the peak related to the second mode does not change significantly with the hazard level. From the obtained results it is evident the flexible equipment with a period similar to the second period of the isolated system may be subject to important resonance phenomena. In the following section it is investigated whether additional damping sources in the superstructure (superstructure damping) or in the isolation system (friction force of flat sliders) can allow to better control the superstructure response.

A final remark needs to be made about axial loads acting on the bearings. The maximum compression load, evaluated at the CLS seismic intensity level on external bearings, is $P_{\max }=922$ $\mathrm{kN}$, as reported in Table 14. This value is significantly lower than the buckling limit $P{ }^{\prime}{ }_{c r}$, reported in the same table and calculated according to the theory about the stability of multi-layered bearings as a function of the maximum attained displacement ([2],[25]). In particular, the buckling limit at zero displacement is given by the following expression

$$
P_{c r}=\sqrt{P_{s} P_{e}}=\sqrt{G A_{s} \cdot \frac{\pi^{2} E I_{s}}{h^{2}}}
$$

where $A_{s}$ and $I_{s}$ are the shear area and moment of inertia accounting for the rigidity of steel shims, $E$ is the rotation modulus and $h$ is the total height of the bearing (a standard thickness of $3 \mathrm{~mm}$ is considered for the steel shims). The critical buckling load in the deformed configuration is then computed through the area reduction method

$$
P_{c r}^{\prime}=P_{c r} \frac{A_{r}}{A}
$$

where $A_{r}$ is the overlapping area in the deformed configuration. More information can be found in [41]. The values reported in Table 4 show that buckling of bearings is avoided up to the CLS intensity level, as confirmed by the dimensionless parameter $1-\left(P_{\max } / P^{\prime}{ }_{c r}\right)^{2}$ reported in the last column of Table 14 which measures the "distance" from the buckling of the bearing in the maximum force/displacement configuration. This parameter is also used by several authors [2] [42] as reduction coefficient of the lateral stiffness of bearings due to the P- $\Delta$ effects . The obtained values are close to 1 up to the CLS intensity level, confirming that the horizontal behaviour is not influenced by the vertical load. At the CLS intensity level, a tensile force is also induced on the bearings but its maximum value is limited $\left(P_{\min }=14 \mathrm{kN}\right)$ and lower than the cavitation load, equal to $P_{c a v}=480 \mathrm{kN}$, calculated assuming a maximum tensile stress of $2 G$, with $G$ conventionally calculated at $100 \%$ of shear strain as suggested in [13].

Table 14 - Maximum axial loads of the bearings, buckling load and horizontal reduction

\begin{tabular}{|c|c|c|c|c|}
\hline & \multicolumn{4}{|c|}{0} \\
\hline & $\begin{array}{l}\boldsymbol{P}_{\max } \\
{[\mathrm{kN}]}\end{array}$ & $\begin{array}{r}\boldsymbol{P}_{\min } \\
{[\mathrm{kN}]}\end{array}$ & $\begin{array}{l}P^{\prime} \boldsymbol{c r} \\
{[\mathrm{kN}]}\end{array}$ & $\begin{array}{c}1-\left(\boldsymbol{P}_{\max } / \boldsymbol{P}_{c r}\right)^{2} \\
{[-1}\end{array}$ \\
\hline OLS & -605 & -282 & -9307 & 1.00 \\
\hline DLS & -661 & -232 & -8350 & 0.99 \\
\hline ULS & -798 & -106 & -5835 & 0.98 \\
\hline CLS & -922 & 14 & -4262 & 0.95 \\
\hline
\end{tabular}
coefficient 


\section{Influence of superstructure damping and sliders friction}

In this section aspects characterizing the performance of real applications are investigated, such as the influence of the superstructure damping and the friction of sliders, are investigated. With reference to the superstructure a damping ratio $\xi_{s}$ equal to $5 \%$ is considered in addition to the reference value $\xi_{s}=2 \%$, which is still common for reinforced concrete isolated structures [33].

Figure 12 shows that the influence of $\xi_{s}$ on maximum floor displacements (including the isolation system displacement) is negligible, whereas the effect on the inter-storey drifts is significant and more and more remarkable as the seismic hazard level increases (Figure 12b). The mean FRS at the ULS intensity obtained with $\xi_{s}=5 \%$ is shown in Figure 13 . Figure 14 compares floor absolute accelerations and response spectra of the top floor obtained for the two cases analysed. This comparison clearly shows that the superstructure damping coefficient strongly reduces the floor accelerations as well as the peak acceleration in correspondence of the second mode of the isolated structure, whereas it has no influence on the peak of the first mode. For frequent events (OLS and DLS intensity levels) and the design one (ULS intensity level), a value of $\xi_{s}=5 \%$ permits to significantly reduce the acceleration peak in correspondence of the second mode (which is lower than $4 \mathrm{~m} / \mathrm{s}^{2}$ for the DLS and just over $6 \mathrm{~m} / \mathrm{s}^{2}$ for the ULS).

a)

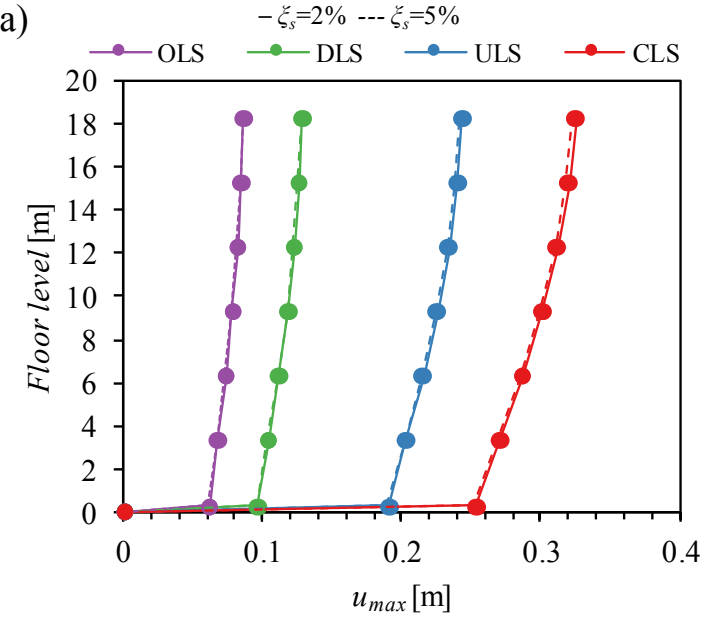

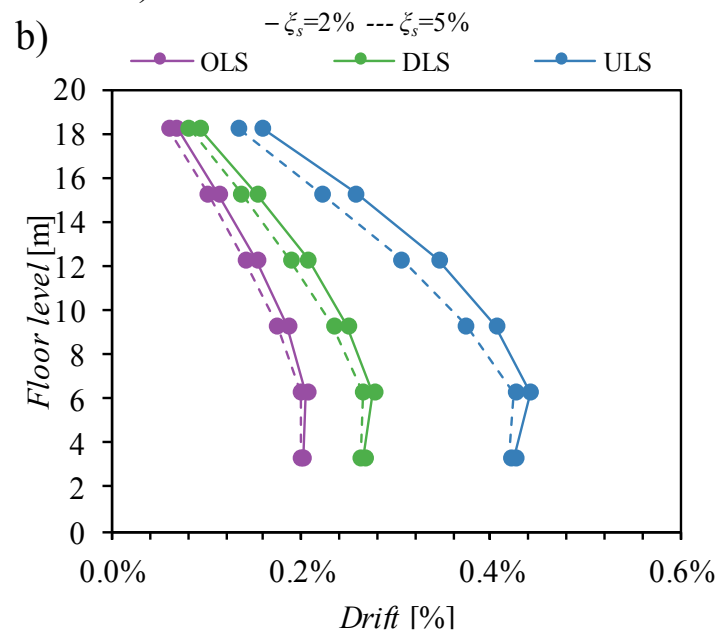

Figure 12 - (a) Floor maximum displacements and (b) maximum inter-storey drifts for $\xi=2 \%$ and $5 \%$

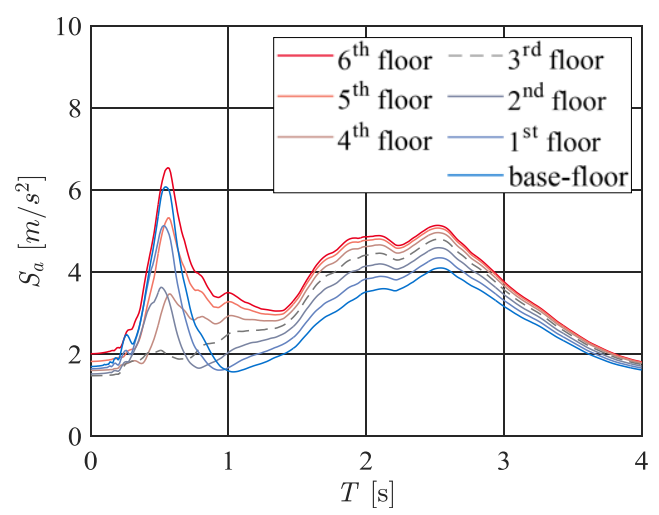

Figure 13 - FRS of all floor at the ULS for $\xi_{s}=5 \%$

Figure 15 shows the influence of the friction coefficient of flat sliders $\left(\mu_{s}\right)$ on the performance of the isolated system. Two values are considered, namely $1 \%$ and $2 \%$ and an elastic-perfectly plastic model with large initial stiffness is used to simulate friction forces. Contrary to the effect of 
superstructure damping, increasing the friction coefficient yields significant reductions of the maximum displacement of the isolation system, while it has a minor effect on superstructure interstorey drifts and floor accelerations, as shown in Figure 15-Figure 17. In particular, floor accelerations do not change or little increase at the base floor level. Thus, a relatively low friction is positive since base displacements are substantially reduced without appreciably increasing superstructure accelerations, as also found in [43].
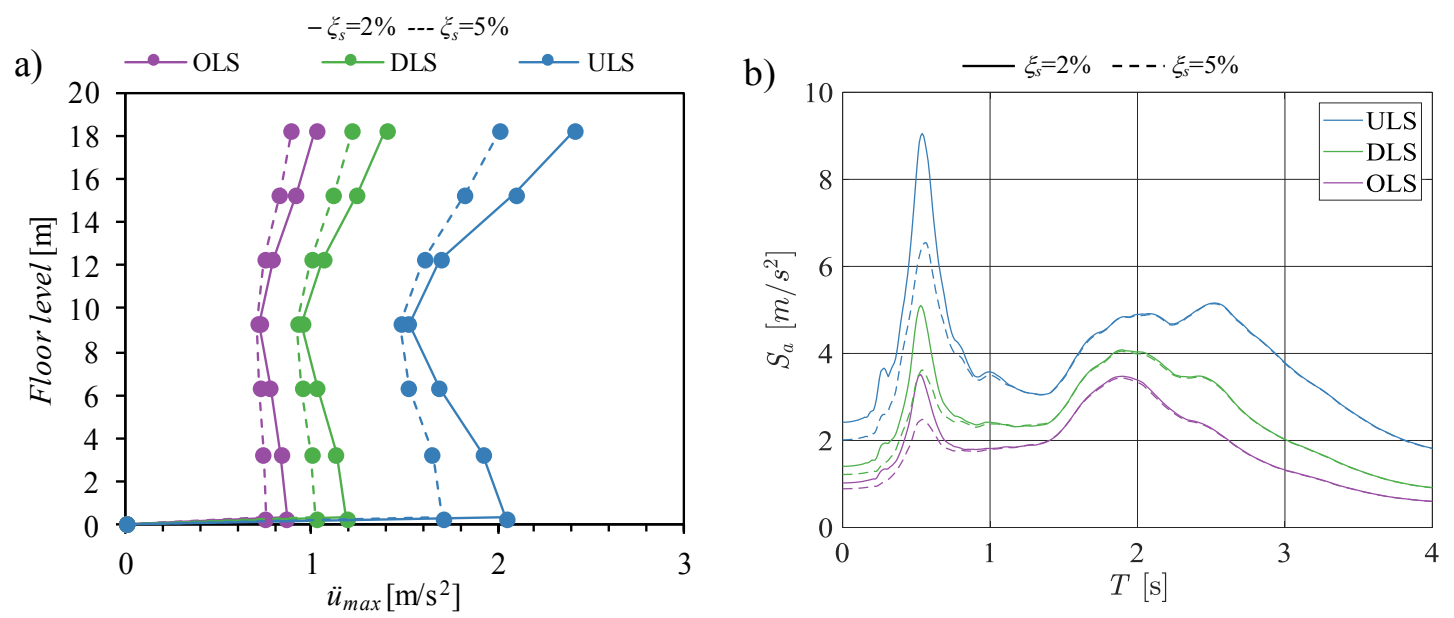

Figure 14 - (a) maximum absolute flooraccelerations and (b) top floor RS for $\xi_{s}=\mathbf{2 \%}$ and $\mathbf{5 \%}$
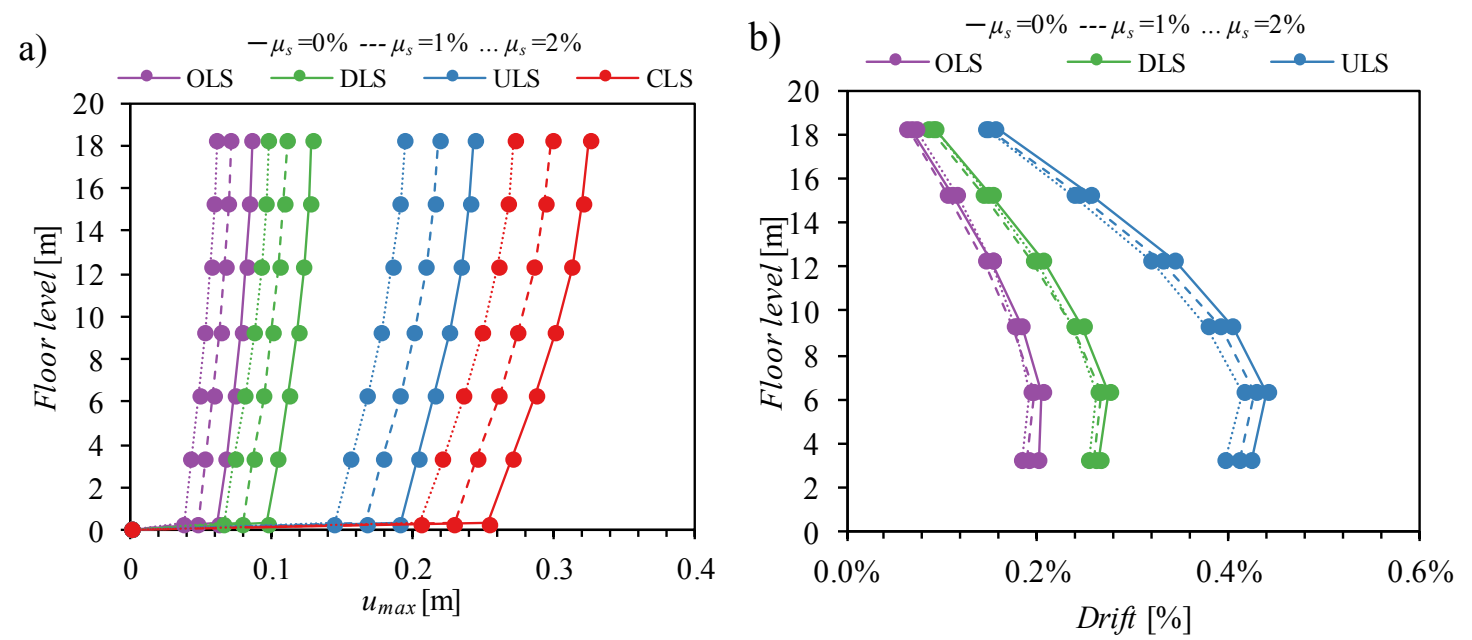

Figure 15 - (a) Floor displacements and (b) maximum inter-storey drifts
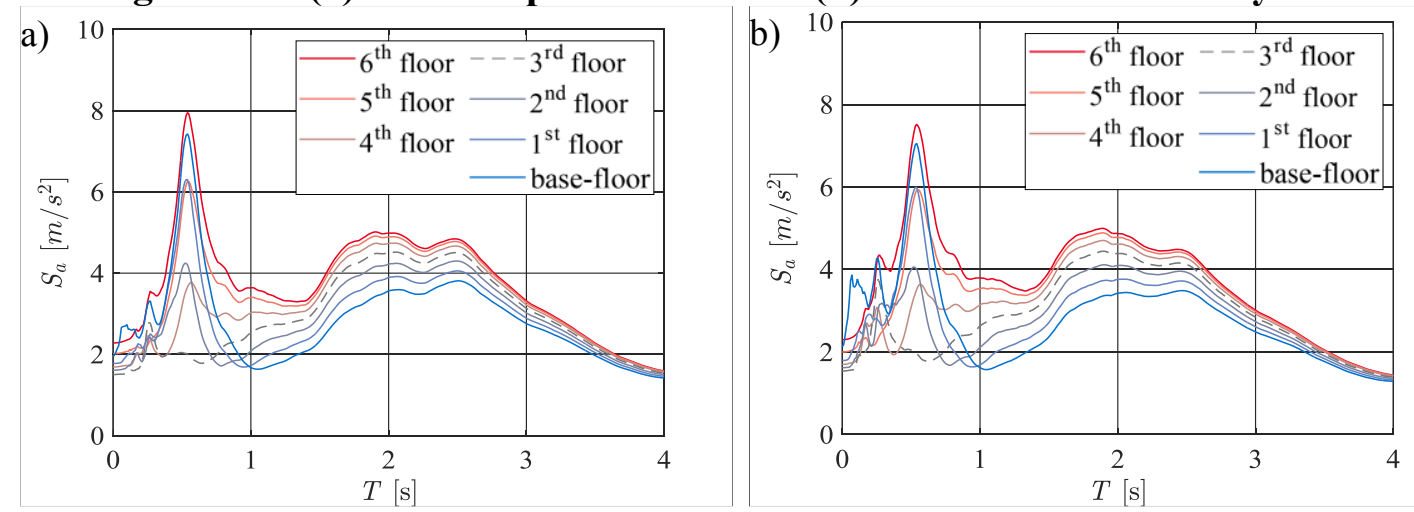

Figure 16 - FRS of all floor at the ULS for (a) $\mu_{s}=1 \%$ and (b) $\mu_{s}=2 \%$ 
However, with regards to FRS, friction forces produce a reduction of the acceleration peak in correspondence of the first mode, whereas the ones in correspondence of the second mode are much less sensible to the friction coefficient. This can be observed in Figure 16 illustrating the mean FRS corresponding to the ULS obtained for $\mu_{s}=1 \%$ and $\mu_{s}=2 \%$ and in Figure 17 comparing the mean FRS of the top floor accelerations for $\mu_{s}=1 \%$ and $\mu_{s}=2 \%$ with the reference case with $\mu_{s}=0 \%$.
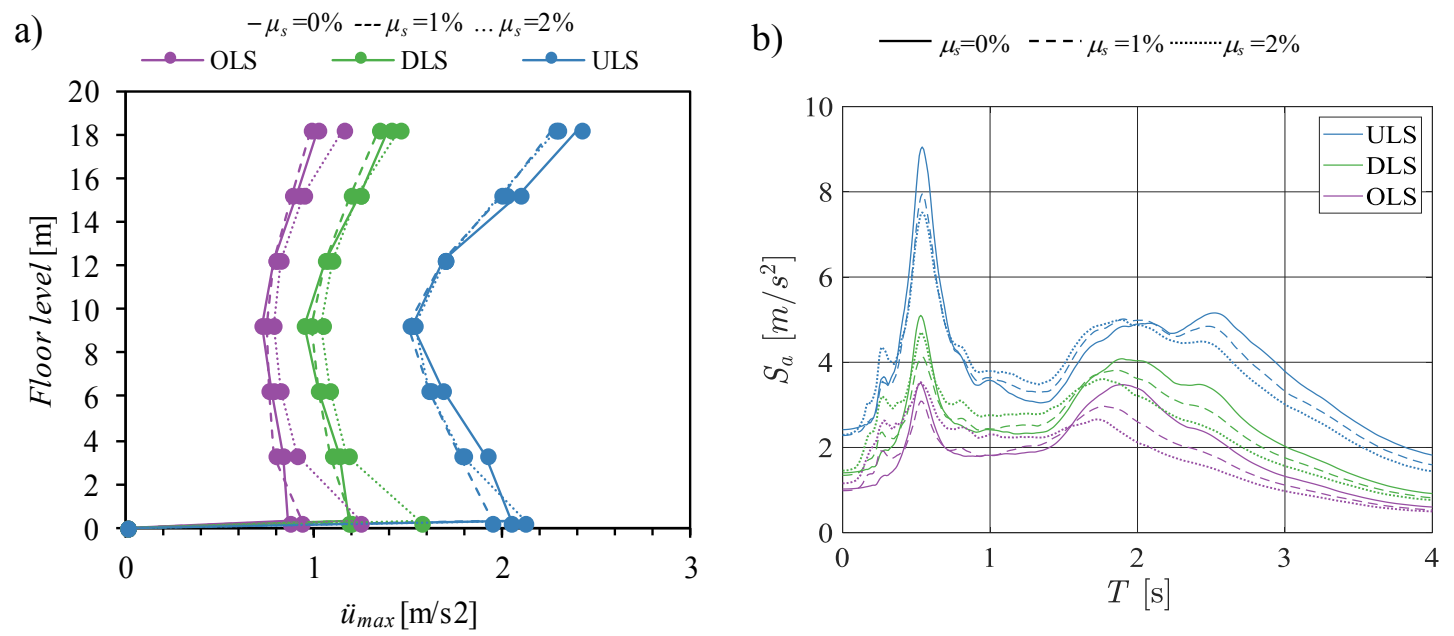

Figure 17 - (a) Maximum absolute floor accelerations and (b) top floor RS for $\mu_{s}=0 \%, 1 \%$ and $2 \%$

\section{CONCLUSION}

This paper investigates the seismic response of structures isolated by high-damping natural rubber (HDNR) bearings under serviceability and design seismic intensity levels. In particular, the effects of the variation of stiffness and damping with the strain amplitude and of the stress-softening are investigated by using an advanced bearing model. After a preliminary parametric study on 2-DOF systems, where results are compared with those of a reference linear viscoelastic model, a M-DOF isolated system with HDNR bearings is analysed in order to evaluate the response at various floors as well as other aspects affecting the seismic performance of a real application. In both the cases, response parameters relevant to the isolation system and the superstructure are evaluated. Floor response spectra are also built to evaluate the performance of acceleration sensitive non-structural components. Based on the results of the analyses carried out on the 2-DOF systems, the following two main conclusions are drawn:

(i) from the bearings displacement demand side, the differences observed between the response provided by the advanced nonlinear model including the stress softening and the reference equivalent linear model are limited at all the hazard levels and for all the case analysed (less than $25 \%$ from the bearing side and less than $35 \%$ from the superstructure side for the OLS);

(ii) the stress softening of HDNR bearings notably increases the record to record variability effects and the resulting dispersion is different for different hazard levels and response parameters, thus it can significantly influence the seismic risk evaluation.

In addition, based on the results of the analysis on the 2-DOF systems and the M-DOF system, some further conclusions can be made:

(i) by reducing the M-DOF system to the equivalent 2-DOF system relative displacements and absolute accelerations of the superstructure floors are accurately estimated, confirming the negligible influence of higher modes; 
(ii) the performance of the superstructure at the serviceability and design limit states is satisfactory, but in the case of flexible superstructure floor response spectra show an amplification in correspondence of the second mode of the isolated system, that becomes very important for the base and top floor of a M-DOF system and for an hazard level equal than the design one;

(iii) the superstructure damping significantly helps to reduce superstructure absolute accelerations and the floor response spectra in correspondence of the second mode of vibration, thus improving the performance of acceleration-sensitive equipment; on the other hand, friction of sliders in hybrid isolation systems mainly affects the bearing deformation, while the superstructure response is only marginally affected.

As a final remark, it should be noted that all the obtained results refer to the selected rubber compound, which has been experimentally tested and used to calibrate the advanced numerical models of HDNR bearings employed for the analyses. A more extensive study should be carried out including different rubber compounds and isolation periods to give more general outcomes. However, these preliminary results allow to conclude that the history dependent behaviour of HDNR bearings may significantly affect the system response and its variability. Thus, seismic codes should prescribe to consider this effect, and should suggest simplified approaches such as the upper and lower bound analysis based on the first and third cycle data. Moreover, seismic codes must stress that equivalent linear models should be used with caution, because they are not able to simulate the excitation of higher modes of the isolated system, resulting in a possible underestimation of the acceleration of non-structural components."

\section{REFERENCES}

[1] Christopoulos C, Filiatrault A. Principles of Passive Supplemental Damping and Seismic Isolation. IUSS Press:

Pavia, Italy, 2006.

[2] Naeim F, Kelly MK. Design of seismic isolated structures. Wiley, New York,1999.

[3] Iervolino I, Spillatura A, Bazzurro P. Seismic Reliability of Code-Conforming Italian Buildings. Journal of Earthquake Engineering 2018; 22: 5-27.

[4] Ragni L, Cardone D, Conte N, Dall'Asta A, Di Cesare A, Flora A, Leccese G, Micozzi F, Ponzo C. Modelling and seismic response analysis of Italian code-conforming base-isolated buildings. Journal of Earthquake Engineering, 2018; 22:198-230.

[5] Dall'Asta A, Tubaldi E, Ragni L. Influence of the nonlinear behavior of viscous dampers on the seismic demand hazard of building frames dampers, Earthquake Engng Struct. Dyn 2016;45(1):149-169.

[6] Scozzese F, Dall'Asta A, Tubaldi E. Seismic risk sensitivity of structures equipped with antiseismic devices with uncertain properties. Structural Safety 2019;77:30-47.

[7] Kelly V, Marsico MR. The influence of damping on floor spectra in seismic isolated nuclear structures. Struct. Control Health Monit. 2015; 22:743-756.

[8] Calvi P.M., Calvi G.M. Historical development of friction-based seismic isolation systems Soil Dynamics and Earthquake Engineering 106 (2018) 14-30.

[9] Barone S, Calvi GM, Pavese A. Experimental dynamic response of spherical friction based isolation devices. J Earthq Eng 2017. http://dx.doi.org/10.1080/13632469.2017.1387201

[10] Mullins L. Softening of rubber by deformation, Rubber Chemistry and Technology 1969, 42(1): 339-362.

[11] Clark PW, Aiken ID, Kelly JM. Experimental studies of the ultimate behaviour of seismically isolated structures, Report No. UCB/EERC-97/18, Earthquake Engineering Research Center, University of California, Berkeley, California, 1997.

[12] Tubaldi E, Ragni L, Dall'Asta A, Ahmadi H, Muhr A. Stress softening behaviour of HDNR bearings: modelling and influence on the seismic response of isolated structures, Earthquake Engng Struct. Dyn 2017; 46(12): 2033-2054.

[13] European Standard EN15129. Anti-Seismic devices. European Committee for Standardization, 2018. 
[14] ASCE/SEI 7-10. Minimum design loads for buildings and other structures. American Society of Civil Engineers : Structural Engineering Institute, Reston, Va 2010.

[15] Madera Sierra, I.E., Losanno, D., Strano, S., Marulanda, J., Thomson, P. Development and experimental behavior of HDR seismic isolators for low-rise residential buildings. Engineering Structures; 2019. 183, 894-906. https://doi.org/10.1016/j.engstruct.2019.01.037

[16] Losanno D., Madera Sierra I.E., Spizzuoco M., Marulanda J., Thomson P. Experimental assessment and analytical modeling of novel fiber-reinforced isolators in unbounded configuration, Composite Structures. 2019 a; 212, 66-82.

[17] Losanno D., Madera Sierra I.E., Spizzuoco M., Marulanda J., Thomson P. Experimental Performance of Unbonded Polyester Fiber Reinforced Elastomeric Isolators under Bidirectional Seismic Excitations, Engineering $\quad$ Structures. 2019 b; (https://doi.org/10.1016/j.engstruct.2019.110003).

[18] Kikuchi M, Nakamura T, Aiken ID. Three-dimensional analysis for square seismic isolation bearings under large shear deformations and high axial loads. Earthquake Engng Struct. Dyn 2010; 39:1513-1531.

[19] Grant DN, Fenves GL, Whittaker AS. Bidirectional modeling of high-damping rubber bearings. Journal of Earthquake Engineering 2004, 8(1):161-185.

[20] McKenna F, Fenves G, Scott M. Computer program OpenSees: open system for earthquake engineering simulation, Pacific Earthquake Engineering Center, University of California, Berkeley, CA, 2006.

[21]Kikuchi M, Aiken ID. An Analytical Hysteresis Model for Elastomeric Seismic Isolation Bearings, Earthquake Engineering and Structural Dynamics 1997, 26(2):215-231.

[22] Ragni L, Tubaldi E, Dall'Asta A, Ahmadi H, Muhr A. Biaxial shear behaviour of HDNR with Mullins effect and deformation-induced anisotropy, Engineering Structures 2018; 154: 78-92.

[23] Yang TY, Konstantinidis D, Kelly JM. The Influence of Isolator Hysteresis on Equipment Performance in Seismic Isolated Buildings. Earthquake Spectra. 2010; 26(1): 275-293.

[24] Isakovic T, Zevnik J, Fischinger M. Floor response spectra in isolated structures subjected to earthquakes weaker than the design earthquake-Part I: Isolation with high-damping rubber bearings Struct. Control Health Monit. 2011; 18:635-659

[25] Kelly JM, Konstantinidis D. Mechanics of Rubber Bearings for Seismic and Vibration Isolation. John Wiley \& Sons, Ltd. 2011.

[26] BS ISO 22762-3: Elastomeric seismic-protection isolators - Part 3: Applications for buildings - Specification, 2005.

[27] Eurocode 8 (EN1998-1) Design of structures for earthquake resistance. European Committee for Standardization, 2013.

[28] CS.LL.PP. Norme tecniche per le costruzioni," Gazzetta Ufficiale della Repubblica Italiana, 2018.

[29]Filiatrautl A., Perrone D., Merino R.J and Calvi GM (2018): Performance-Based Seismic Design of Nonstructural Building Elements, Journal of Earthquake Engineering, DOI: 10.1080/13632469.2018.1512910

[30] Calvi PM, Sullivan TJ. Estimating floor spectra in multiple degree of freedom structures. Earthq Struct 2014;7(1):17-38.

[31] Dall'Asta A, Ragni L. Dynamic systems with high damping rubber: non linear behaviour and linear approximation. Earthquake Engng Struct. Dyn 2008; 37(13), 1511-1526.

[32] Ryan KL, Polanco J. Problems with Rayleigh Damping in Base-Isolated Buildings. Journal of Structural Engineering 2008; 134(11): 1780-1784.

[33] Pant D, Wijeyewickrema A, ElCawady MA. Appropriate viscous damping for nonlinear timehistory analysis of base-isolated reinforced concrete buildings. Earthquake Engng Struct. Dyn 2013; 42(15): 2321-2339

[34] Losanno, D., Hadad, H.A., Serino, G. Design charts for eurocode-based design of elastomeric seismic isolation systems. Soil Dynamics and Earthquake Engineering. 2019; 119, 488-498. https://doi.org/10.1016/j.soildyn.2017.12.017

[35] Occhiuzzi, A. Additional viscous dampers for civil structures: Analysis of design methods based on effective evaluation of modal damping ratios. Engineering Structures 2009; 31, 1093-1101. https://doi.org/10.1016/j.engstruct.2009.01.006

[36] Lubkowski ZA. Deriving the Seismic Action for Alternative Return Periods According to Eurocode 8. 10th European Conference on Earthquake engineering, 2010. Ohrid.

[37] Ancheta TD, Darragh RB, Stewart JP, Seyhan E, Silva WJ, Chiou BSJ, et al. NGA-West2 Database. Earthquake Spectra 2014; 30(3): 989-1005.

[38] Montuori GM, Mele E, Marrazzo G, Brandonisio G, De Luca A. Stability issues and pressure- 
shear interaction in elastomeric bearings: the primary role of the secondary shape factor. Bulletin of Earthquake Engeneering, 2016; 14:569-597.

[39] Castaldo P, Tubaldi E. Influence of FPS bearing properties on the seismic performance of base- isolated structures. Earthquake Engng Struct. Dyn. 2015; 44(15): 2817-2836.

[40] Chimamphant S, Kasai K. Comparative response and performance of base-isolated and fixedbase structures Earthquake Engng Struct. Dyn. 2016; 45:5-27.

[41] Kumar M. Seismic isolation of nuclear power plants using elastomeric bearings. Ph.D. Dissertation. Buffalo (NY): University at Buffalo, The State University of New York; 2015.

[42] Kumar M, Whittaker AS, e Constantinou MC. An Advanced Numerical Model of Elastomeric Seismic Isolation Bearings. Earthquake Engng Struct. Dyn. 2014;43(13): 1955-1974

[43] Makris N, Changt SP. Effect of viscous, viscoplastic and friction damping on theresponse of seismic isolated structures. Earthquake Engng Struct. Dyn 2000; 29:85-107. 